
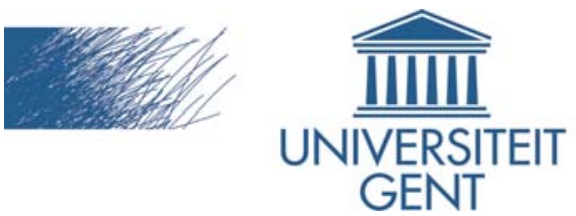

biblio.ugent.be

The UGent Institutional Repository is the electronic archiving and dissemination platform for all UGent research publications. Ghent University has implemented a mandate stipulating that all academic publications of UGent researchers should be deposited and archived in this repository. Except for items where current copyright restrictions apply, these papers are available in Open Access.

This item is the archived peer-reviewed author-version of: Continuous direct compression as manufacturing platform for sustained release tablets

Authors: Van Snick B., Holman J., Cunningham C., Kumar A., Vercruysse J., De Beer T., Remon J.P., Vervaet C.

In: International Journal of Pharmaceutics 2017, 519(1-2): 390-407

To refer to or to cite this work, please use the citation to the published version:

Van Snick B., Holman J., Cunningham C., Kumar A., Vercruysse J., De Beer T., Remon J.P., Vervaet C. (2017)

Continuous direct compression as manufacturing platform for sustained release tablets In-vivo evaluation of apocynin for prevention of Helicobacter pylori-induced gastric. International Journal of Pharmaceutics 519(1-2): 390-407

DOI: 10.1016/j.ijpharm.2017.01.010 


\title{
Continuous direct compression as manufacturing platform for sustained release tablets
}

\author{
Authors \\ B. Van Snick', J. Holman², C. Cunningham³, A. Kumar', J. Vercruysse', T. De Beer ${ }^{4}$, J.P. Remon', C. Vervaet' \\ 'Laboratory of Pharmaceutical Technology, Ghent University, Ghent, Belgium. \\ 2GEA APC Pharma Solids, Eastleigh, United Kingdom. \\ ${ }^{3}$ Colorcon Inc., Harleysville, PA, USA \\ ${ }^{4}$ Laboratory of Process Analytical Technology, Ghent University, Ghent, Belgium
}

\section{Corresponding author:}

Institution: Laboratory of Pharmaceutical Technology

Address: Ghent University, Ottergemsesteenweg 460, 9000, Gent, Belgium

Tel: 00329264

Fax: 00329264

e-mail: chris.vervaet@ugent.be 


\begin{abstract}
This study presents a framework for process and product development on a continuous direct compression manufacturing platform. A challenging sustained release formulation with high content of a poorly flowing low density drug was selected. Two HPMC grades were evaluated as matrix former: standard Methocel CR and directly compressible Methocel DC2. The feeding behavior of each formulation component was investigated by deriving feed factor profiles. The maximum feed factor was used to estimate the drive command which strongly depended upon the density of the material. Furthermore, the shape of the feed factor profile allowed definition of a customized refill regime for each material. Inline NIRs was used to estimate the residence time distribution (RTD) in the mixer and monitor blend uniformity. Tablet content and weight variability were determined as additional measures of mixing performance. For $\mathrm{CR}$, the best axial mixing (i.e. feeder fluctuation dampening) was achieved when an impeller with high number of radial mixing blades operated at low speed. However, the variability in tablet weight and content uniformity deteriorated under this condition. One can therefore conclude that balancing axial mixing with tablet quality is critical for Methocel CR. However, reformulating with the direct compressible Methocel DC2 as matrix former improved tablet quality vastly. Furthermore, both process and product were significantly more robust to changes in process and design variables. This observation underpins the importance of flowability during continuous blending and die-filling. At the compaction stage, blends with Methocel CR showed better tabletability driven by a higher compressibility as the smaller $\mathrm{CR}$ particles have a higher bonding area. However, tablets of similar strength were achieved using Methocel DC2 by targeting equal porosity. Compaction pressure impacted tablet properties and dissolution. Hence controlling thickness during continuous manufacturing of sustained release tablets was crucial to ensure reproducible dissolution.
\end{abstract}




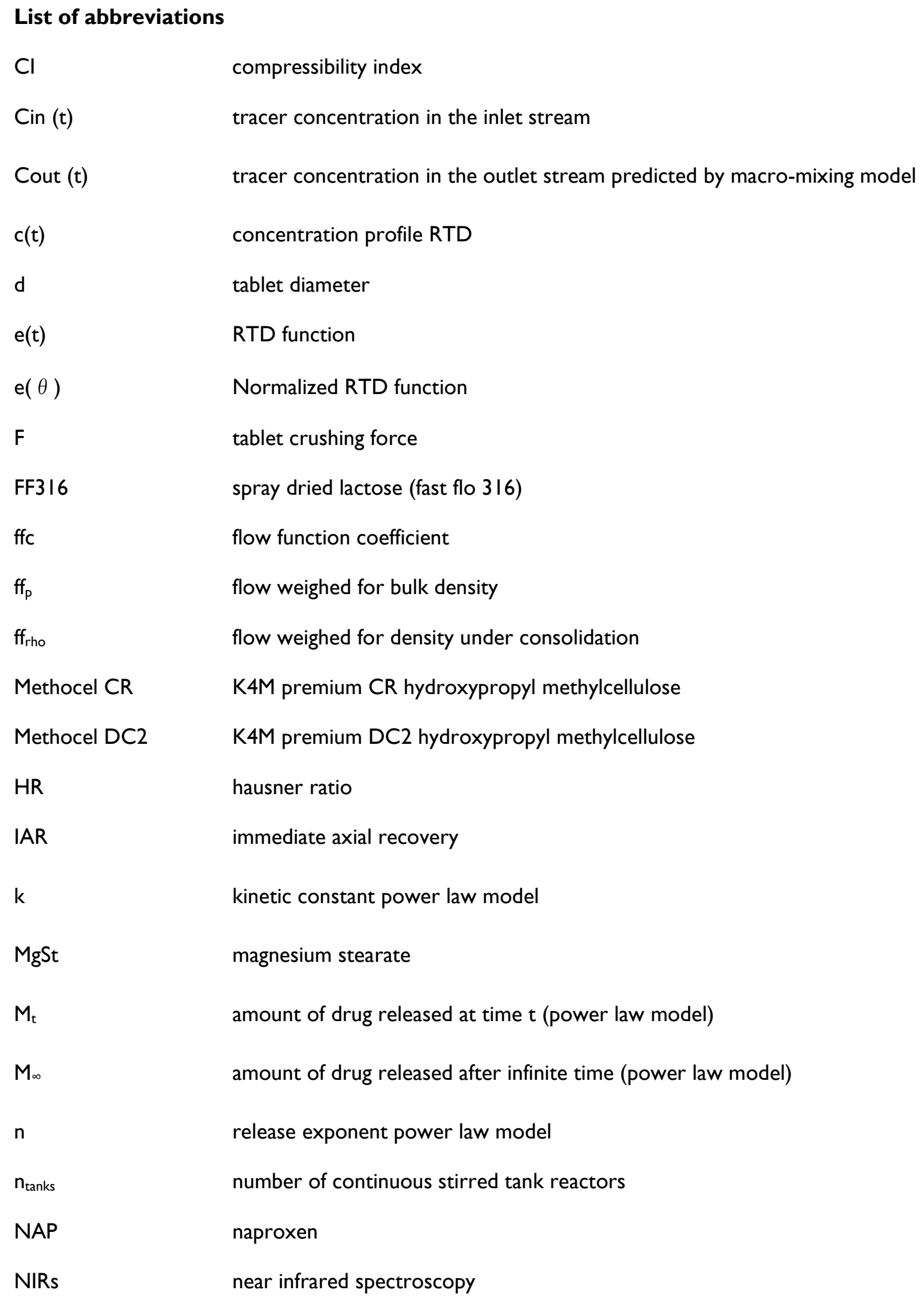


rpm

RSD

RSD $_{\text {Cout }}$

$\mathrm{RSD}_{\mathrm{cu}}$

$\mathrm{RSD}_{\mathrm{wv}}$

$\mathrm{RSD}_{\text {ss }}$

$\mathrm{RSD}_{\text {if }}$

RTD

$\mathrm{SiO}_{2}$

Starch 1500

$\mathrm{t}_{20 \%}$

$t_{50 \%}$

$\mathrm{T}$

$t_{m}$

$t_{\min }$

$\mathrm{V}_{\text {screw }}$

$\mathrm{Q}^{2}$

$\varepsilon_{\text {powder }}$

$\varepsilon_{\text {tablet }}$

$\varepsilon$ fill plug-flow volume fraction

Partial Least Square

Péclet number

coefficient of determination

radial mixing blade

revolutions per minute

residual standard deviation

residual standard deviation on Cout of macro-mixing model

residual standard deviation on tablet content

residual standard deviation on tablet weight

steady state blend uniformity, residual standard deviation predicted NAP content

short term blend uniformity, residual standard deviation in case of ideal feeding

residence time distribution

fumed silica

partially pre-gelatinized starch

time (h) to reach $20 \%$ drug release

time $(\mathrm{h})$ to reach $50 \%$ drug release

tablet thickness

mean residence time

minimum residence time or lag time

volume dispensed per screw revolution

goodness of prediction

powder porosity

tablet porosity

screw flight fill fraction 
$\rho_{\text {app }}$

Pbulk

$\rho_{\text {consolidation }}$

$\rho_{\text {screw }}$

$\rho_{\text {tapped }}$

$\rho_{\text {true }}$

$\sigma_{t m^{2}}$

$\sigma^{2}$

$\Theta$

$\omega_{\text {screw }}$ apparent tablet density

bulk density

density under consolidation

density at the screw inlet

tapped density

true density

variance

normalized variance

dimensionless time

screw rotation rate 


\section{I Introduction}

2 Interest in continuous processing is gaining momentum for pharmaceutical drug product manufacturing.

3 Although drug products are traditionally manufactured via a series of batch-wise unit operations (Engisch

4 and Muzzio, 2015), continuous processing offers several advantages to improve the manufacturing

5 efficiency of solid dosage forms: reduced costs through faster development and less scale-up, smaller

6 equipment footprint and elimination of intermediate storage (Vercruysse et al., 2013). Implementation of

7 in-line process analyzers allows to monitor continuous processes which improves process understanding.

8 This enables the design of a process control and real-time-release strategy which should ultimately improve

9 the quality of the end product (Fonteyne et al., 2015; Simonaho et al., 2016).

I0 Although direct compression is an inherently continuous technique, simple unit operations preceding II tableting (i.e. weighing and blending) are historically performed in batches. To enable continuous direct compression, the integration of continuous powder feeding units, a continuous dry powder mixer and tablet press is required. A handful of research papers recently described the feeding unit operation 14 (Cartwright et al., 2013; Engisch and Muzzio, 20I4, 2012; W. E. Engisch and Muzzio, 2015; Meier et al., 15 2016). Feeders can transfer problems of composition and flow rate variability to subsequent unit operations when their flow rate variability is not well balanced with the amount of axial mixing within the blender. Therefore, the ability to accurately dose a powder over time is a key challenge within the overall manufacturing process. Continuous mixing studies previously focused on the influence of process and design variables on the mixing efficiency and flow behavior within mixers (Pernenkil and Cooney, 2006). Multiple models are available in the literature to describe mixing and transport of particles through

2I a continuous mixer (Fogler, 2006). The main limitation of using residence time distribution (RTD) as a 22 predictive tool for mixing performance (Levenspiel, 1999) is its inability to capture micro-mixing. This is 23 especially important for pharmaceutical blending processes as they combine high product uniformity requirements with small sample sizes. Studies correlating mixing performance with RTD suggested better mixing performance when the RTD is broader (Gao et al., 20II) whilst other studies suggested the performance is governed by the number of revolutions (Vanarase et al., 2010; Portillo et al., 2008). Due to its importance in batch-wise processing, an impressive number of experimental and conceptual 28 compaction studies have been presented (Yu et al., 20I4). Patel et al. (2006) underpinned the importance of material properties and tableting speed on compressibility, tabletability and compactibility

30 This work is an extension of previous studies as experimental and/or conceptual knowledge was applied 31 to each unit operation of an integrated continuous direct compression process. Reports on 32 characterization of integrated from-powder-to-tablet continuous manufacturing platforms remain limited 

et al., 2013). Moreover, none of the described systems utilized an automated hopper refill system which is a critical point within the manufacturing process (W. E. Engisch and Muzzio, 20I5). Continuous direct compression of an immediate release formulation was first reported by Järvinen et al. (2013). Tablets with good mechanical properties were produced although pharmacopeial uniformity requirements were not met under some conditions. The continuous manufacturing of extended release tablets via continuous direct compression was up to now exclusively investigated by Ervasti et al. (2015). They mainly investigated the impact of particle size (active and HPMC), drug load and mixer speed on product quality. HPMC particle size was a critical material attribute as it impacted the quality attributes of sustained release tablets such as weight variability and tablet strength (Ervasti et al., 2015). Tablet properties were more robust when a better flowing HPMC was incorporated as hydrophilic matrix former although drug release remained prone to mixer settings. Moreover, tablet quality showed significant variability over time as well as within one grab sample. In addition, the mixing performance was not related to the powder flow behavior within the mixer. Furthermore, a low system flow rate was selected $(3.5 \mathrm{~kg} / \mathrm{h})$ throughout their study. Clearly, significant challenges need to be overcome to enable continuous direct compression of sustained release formulations. Among them, in depth characterization of the continuous mixing stage, improving product quality and exploring the impact of operating at flow rates relevant for pharmaceutical manufacturing.

5I This paper is organized as follows: the employed continuous direct compression manufacturing platform is introduced in section 2. The used materials and applied methods are described in sections 3 and 4, respectively. The obtained results are discussed in section 5. First, the properties of each material and 54 blend are elucidated (5.I). Second, the results of a fundamental loss-in-weight feeder characterization 55 procedure are interpreted (5.2). Third, an experimental design was conducted with HPMC CR grade to understand the impact of impeller configuration and speed on process and product (5.3). Next, the impact of drug load on the mixing performance was verified and related to the blend properties and consecutive powder flow within the mixer and (5.4). Finally, the impact of HPMC grade and flow rate on was assessed (5.5). Conclusions of this work are presented in section 6.

\section{Continuous direct compression equipment}

6I The CDC-50 (GEA APC Pharma Solids, Wommelgem, Belgium) combines material handling, loss-in-weight

62 feeding, two stage continuous blending, compression and in-line NIRs to monitor blend uniformity in an integrated manufacturing system (figure I). 
The individual materials are transferred to dedicated top up systems through vacuum conveying or gravity. The vacuum top up system consists of a conical hopper (3.2 L) with level sensor to regulate pneumatic powder supply. The gravity feed system consists of a cylindrical feed tube and is used when powders undergo triboelectric charging during vacuum transfer. Both systems are connected to a rotating top-up valve $(0.4,0.8,1.2$ or I.6 L) which allows consistent hopper refill of the screw feeder at optimal fill level.

Up to 6 GEA compact twin screw feeders can be integrated on the manufacturing system. The feeders can be distributed over two feeding stations positioned at the inlet of the first and second continuous mixer which holds a maximum of 6 and 2 feeders, respectively. The powder pump rests on top of the load cell ( $2 \mathrm{~kg}$ range) and consists of a $2 \mathrm{~L}$ hopper connected with a twin screw feeding system. An impeller rotates horizontally above the twin screws to ensure consistent screw flight filling and prevent bridging.

The blending process is conducted by two consecutive GEA continuous dry powder blenders which separate the blending process into two distinct stages: the first blender is used for intensive mixing, whereas shear-sensitive materials are introduced in the second blender. The GEA continuous dry powder blender consists of a cylindrical processing chamber in which an impeller is rotating. The impeller is a shaft which holds 60 mixing blades that have a fixed tolerance with the upwards tilted $\left(15^{\circ}\right)$ processing chamber. Each blade can be positioned as a transport blade or a radial mixing blade (RMB) oriented respectively at $45^{\circ}$ or $0^{\circ}$ along the axis of the shaft. The mixer has a rotation rate that ranges from 45 to $450 \mathrm{rpm}$.

The blend is collected at the outlet of the second blender and guided via a borosilicate feed tube into the feed frame of the tablet press (MODUL TM S, GEA APC Pharma Solids, Halle, Belgium). A level sensor detects the fill level of the feed tube, which is maintained at its target during manufacturing by modulating the turret speed via a proportional-integral-derivate controller. A fiber optic contact probe (Lighthouse ${ }^{\mathrm{TM}}$ probe, GEA APC Pharma Solids, Wommelgem, Belgium) is connected to an NIR spectrometer (Tidas $\mathrm{P}$ analyzer, J\&M Analytik, Essingen, Germany) and implemented in the feed tube just before the inlet of the feed frame. Spectra are recorded every second during tablet production. The MODUL TM $S$ is equipped with moving rollers at the pre-compression station and fixed rollers at the main compression station.

\section{Materials}

Naproxen sodium was selected as a freely soluble cohesive model drug. The formulation contained $30 \%$ w/w naproxen sodium ('NAP', Zhejiang Charioteer Pharmaceutical Company, Tongyuanxi, China), 30\% w/w hydroxypropyl methylcellulose (Methocel K4M premium CR, 'CR', Dow, Michigan, USA), 29\% w/w spray dried lactose (Fast Flo 316, 'FF316', Kerry, Naas, Ireland), 10\% w/w partially pre-gelatinized starch ('Starch 1500', Colorcon, Harleysvile, USA), 0.5\% w/w fumed silica (CAB-O-SIL M-5P, 'SiO2', Cabot, 
Amersfoort, The Netherlands) and 0.5\% w/w magnesium stearate (Ligamed MF-2-V, 'MgSt', Peter Greven,

96 Venlo, The Netherlands). Methocel CR grade was compared to its Methocel DC2 equivalent to study the 97 impact of HPMC particle size and flow.

98

112 Hausner ratio $=\frac{\text { Initial volume }}{\text { Volume after } 1250 \text { taps }}$

113 Compressibility index $(\%)=100 \times \frac{\text { Initial volume }- \text { Volume after } 1250 \text { taps }}{\text { Initial volume }}$

II4 The true density of all raw materials and blends were measured using helium pycnometry (AccuPyc I330,

II5 Micrometrics, Norcross, U.S.A.) at an equilibration rate of $0.0050 \mathrm{psig} / \mathrm{min}$ with the number of purges set 116 to 10 . The powder porosity, $\varepsilon_{\text {powder, }}$ was calculated (3) where $\rho_{\text {true }}$ denotes true density $(\mathrm{g} / \mathrm{ml})$.

$117 \quad \varepsilon_{\text {powder }}=1-\frac{\rho_{\text {bulk }}}{\rho_{\text {true }}}$

\section{I.3 Flowability of powders}


II9 Powder flowability was measured in triplicate using a ring shear tester (Type RST-XS, Dietmar Schulze

120 Schüttgutmesstechnik, Wolfenbuttel, Germany). The applied normal load at pre-shear was $1000 \mathrm{~Pa}$,

121 afterwards the powders were sheared under three different consolidation stresses: 400, 600 and $800 \mathrm{~Pa}$.

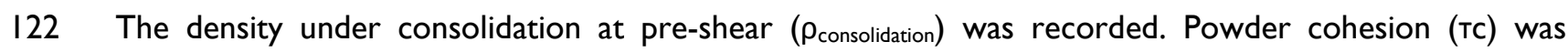

I23 determined using the yield locus to estimate the shear stress at zero normal load. The flow function

I24 coefficient (ffc) was used to evaluate flowability. Furthermore, the density-weighed flow was calculated to 125 assess the flow under gravity and expressed as $\mathrm{ff}_{\mathrm{p}}(4)$ and $\mathrm{ff}_{\text {rho }}(5)$.

$126 f f_{p}=f f c \times \rho_{\text {bulk }}$

$127 f f_{\text {rho }}=f f c \times \rho_{\text {consolidation }}$

\subsection{Loss in weight feeding}

\subsection{Experimental set up}

130 The feeding behavior of materials included in this study was verified on the compact feeder (GEA,

I31 Wommelgem, Belgium). First, screws were primed prior to each run. Subsequently, the hopper was gently

I32 filled up to $2 \mathrm{~L}$. The corresponding weight ( $\mathrm{g}$ ) was recorded and considered as maximal. The hopper was

I33 run completely empty while the operation mode (volumetric or gravimetric), screw speed (rpm), net

134 weight $(\mathrm{g})$, feed factor $(\mathrm{g} / \mathrm{screw}$ revolution) and feedrate $(\mathrm{g} / \mathrm{s})$ were logged every second. The drive

I35 command (\%) was calculated by normalizing the screw speed with the max screw speed (462 rpm).

\subsubsection{Feed factor decay}

137 The volumetric feedrate $(\mathrm{mL} / \mathrm{s})$ of any screw feeder can be calculated (Engisch and Muzzio, 20I4):

139 Where $\mathrm{V}_{\text {screw }}$ ( $\mathrm{mL} /$ revolution), $\varepsilon_{\text {fill }}, \omega_{\text {screw }}$ (revolutions/s) denote the volume dispensed per screw I40 revolution, screw flight fill fraction and screw rotation rate, respectively. The volume dispensed per screw 14I revolution is $4.86 \mathrm{I}$ or $2.40 \mathrm{I} \mathrm{mL}$ for screws with a pitch of 20 or $10 \mathrm{~mm}$, respectively. The fill fraction 142 accounts for incomplete screw flight filling due to poor powder flow in the screw flights or screw layering. 143 In order to calculate the gravimetric feed rate $(\mathrm{g} / \mathrm{s})$ one should multiply volumetric feedrate with the 144 density $(\mathrm{g} / \mathrm{mL})$ of the material at the screw inlet, $\rho_{\text {screw }}$ :

145 Gravimetric feedrate $=\rho_{\text {screw }} \times$ volumetric feedrate 
I46 At a fixed screw speed, the gravimetric feedrate over time (8) is solely related to the feed factor over time

147 (9). If one assumes that $\varepsilon_{\text {fill }}$ remains constant during steady state feeding, $\rho_{\text {screw }}(t)$ need to be determined

148 in order to predict the gravimetric feedrate over time. Furthermore, a theoretical feed factor value is

I49 calculated by substituting $\rho_{\text {screw }}$ with $\rho_{\text {bulk }}$ in equation 9 and assuming complete screw flight filling. It was

I50 then evaluated if the theoretical feed factor provides a good estimate of the actual value.

I5I Gravimetric feedrate $(t)=$ feed factor $(t) \times \omega_{\text {screw }}$

Feed factor $(t)=\rho_{\text {screw }}(t) \times V_{\text {screw }} \times \varepsilon_{\text {fill }}$

153 The feed factor versus weight profiles, further referred to as feed factor profiles, indicate the feed factor

I54 and hence also the density at screw inlet decay with a decreasing net weight in the hopper. To compare

I55 the feeding behavior of materials with different density, the variable hopper fill level $(10)$ is introduced to

156 normalize the net hopper weight for the maximum weight in the hopper. The maximum feed factor is

I57 typically observed at higher fill levels where the feed factor remains relatively stable. It can be used to

I58 estimate the feeding capacity for a particular material. Normalized feed factor profiles were constructed

159 by normalizing the feed factor for the maximum feed factor (II). These normalized feed factor profiles

I60 allow to study the shape of the feed factor decay in case of absolute differences in the maximum feed

I6I factor. Hence normalized feed factor profiles allow to define a minimum fill level and select a suitable refill 162 regime for each material.

163 Fill level $(t)=\frac{\text { Net weight }(t)}{\text { Maximum weight }} \times 100$

164 Normalized feed factor $(t)=\frac{\text { feed factor }(t)}{\text { Maximum feed factor }} \times 100$

\subsection{Continuous blending}

\subsection{Experimental set-up}

167 At the first blending stage, the impact of impeller rotation rate and configuration was investigated according

168 to a full factorial design of experiments where each factor was tested at three levels. The impeller configuration (figure 2) was considered as a quantitative factor by extending the shear zone in the middle of the impeller with RMB (8, 12 or 16). The impeller speed was set at 200, 300 and $400 \mathrm{rpm}$ for each

17I impeller configuration. The flow rate $(25 \mathrm{~kg} / \mathrm{h})$, second blender settings and formulation (CR grade)

I72 remained fixed during this experimental design. The investigated responses were flow behavior within the

I73 continuous mixer (fill level, strain, RTD analysis and modeling), mixing performance (BU) and tablet quality 
174 (content uniformity and weight variation). Additional experiments were performed to evaluate the impact

175 of HPMC grade. Finally, the feasibility of operating at high flow rates (50 and $75 \mathrm{~kg} / \mathrm{h}$ ) was explored for

176 the better flowing Methocel DC2-based formulation. For these trials tablet quality characterization was

177 extended with tensile strength and dissolution.

\subsubsection{Development and verification of NIR blend uniformity models}

179 NIR-based Partial Least Square (PLS) regression models were constructed during in-line monitoring of 180 NAP content. Data analysis was performed using SIMCA 14 (Umetrics AB, Umeå, Sweden). The PLS I8I models were developed by regressing 2750 (II calibration standards $\times 250$ spectra/standard) inline 182 collected and pre-processed NIR spectra with their corresponding concentration of NAP. Spectra were 183 collected in the spectral region from 1091 to $2107 \mathrm{~nm}$ with a pixel dispersion of $3.97 \mathrm{~nm}$. Each 184 spectrum was collected with an integration time of $60 \mathrm{~ms}$ and averaged over seven scans such that 185 NIRs samples approximated the weight of unit dose (i.e. $400 \mathrm{mg}$ ). Spectra were recorded every second. 186 The verification set consisted of II independent verification standards which each contained 50 spectra. 187 At nominal concentration (30.5\%), three independent calibration and verification runs were performed. 188 The NAP level of each standard is depicted in table 3.

189 Two spectral regions specific for NAP were selected for analysis (I I30-1230 and I404-1739 nm). These 190 spectral regions were standard normal variate corrected and mean-centered before PLS was performed.

191 Three PLS components were chosen as the goodness of prediction of the model did not significantly 192 improved $\left(\mathrm{Q}^{2}=0.99\right)$ when adding extra components. The scores and loading plot of the first component 193 confirmed this component represents the variation in NIR spectra caused by the difference in NAP 194 concentration. Positive peaks in the loading of the first component corresponds to spectral peaks of NAP 195 which confirmed thereby the specificity of the method. A higher score for component I therefore indicates 196 a higher NAP concentration.

197 Standard cross-validation was applied by dividing the dataset in 7 groups. The root mean squared error of 198 cross validation of this three component PLS model was $0.52 \%(\mathrm{w} / \mathrm{w})$. The predictive performance of this 199 model was subsequently evaluated by predicting the concentration for all verification standards (table 3 ). 200 This resulted in an overall root mean squared error of prediction value of $0.5 \mathrm{I} \%(\mathrm{w} / \mathrm{w})$. A linear relation 201 between target concentration and model predicted concentration was found $\left(R^{2}=0.99\right)$.

\section{$202 \quad$ 4.3.3 RTD estimation and analysis}


203 The RTD was estimated by performing an impulse response test: a pulse of NAP was introduced at the 204 inlet of the first blender whilst its concentration was monitored via in-line NIRs as a function of time at 205 the system outlet (feed tube of the tablet press). The response is the concentration as a function of time 206 (s), i.e. the concentration profile $c(t)$. The amount of tracer $(\max 25 \mathrm{~g})$ was selected such that the system 207 response was detectable with near infrared spectroscopy and within the calibrated range (section 4.3.2). 208 Furthermore, the pulse size was limited to ensure the steady state of the process was not disturbed. The $209 \mathrm{c}(\mathrm{t})$ curve was used to calculate the RTD function $e(t)$ with equation $(12)$. Note that $e(t)$ normalizes the 210 concentration profile $\mathrm{c}(\mathrm{t})$ by the total amount of tracer $\int_{0}^{\infty} c(t) d t$.

$211 \quad e(t)=\frac{c(t)}{\int_{0}^{\infty} c(t) d t}$

212 The RTD function e $(t)$ and mean residence time $\left(t_{m}\right)$ were used to obtain the normalized residence time

213 which is calculated as $\mathrm{e}(\theta)=\mathrm{e}(\mathrm{t}) \times \mathrm{t}_{\mathrm{m}}$ and where $\theta$ is the dimensionless time, i.e. $\theta=\frac{\mathrm{t}}{\mathrm{t}_{\mathrm{m}}}$. The variance

$214\left(\sigma_{t m^{2}}\right)$ and normalized variance $\left(\sigma_{\theta}^{2}\right)$ are measures of the spread of the RTD and normalized RTD curve,

215 respectively. The RTDs were quantitatively assessed by calculating $\mathrm{t}_{\mathrm{m}}, \sigma_{\mathrm{tm}}{ }^{2}$ and $\sigma^{2}$ (equation $13-15$ )

216 (Fogler, 2006). By treating the boundary condition of the mixer as a closed system with no axial or radial

217 variation in upstream and downstream concentrations to axial dispersion model, Péclet number $(\mathrm{Pe})$ was

218 calculated using equation 16 (Kumar et al., 2014). The dimensionless Péclet number is the ratio of the rate

219 of convection and dispersion. Further interpretation of these RTD measures is described in section 5.3.I.

$220 \quad t_{m}=\frac{\int_{0}^{\infty} t \cdot e(t) d t}{\int_{0}^{\infty} e(t) d t}$

221 $\quad \sigma_{t_{m}}{ }^{2}=\frac{\int_{0}^{\infty}\left(t-t_{m}\right)^{2} \cdot e(t) d t}{\int_{0}^{\infty} e(t) d t}$

$222 \sigma_{\theta}^{2}=\frac{\sigma t_{m}^{2}}{t_{m}^{2}}$

$223 \frac{\sigma t_{m}^{2}}{t_{m}^{2}} \approx \frac{2 P e-2+2 \cdot e^{-P e}}{P e^{2}}$

$224 \quad$ 4.3.4 RTD Modeling

225 A non-ideal flow model has been used to describe the powder flow inside the continuous mixer: the tanks

226 in series model with plug-flow volume fraction was selected to fit the normalized RTDs, $e(\theta)$. The model

227 (17) is a three parameter flow model (Levenspiel, 1999). 
$228 e(\theta)=\frac{b[b(\theta-p)]^{n-1}}{(n-1) !} \exp [-b(\theta-p)]$

229 Where $n=n_{\text {tanks }}=$ number of continuous stirred tank reactors, $p=\frac{t_{\min }}{t_{m}}$ and $b=\frac{n}{1-p}(18)$

230 Where $t_{\min }$ is the minimum residence time and $p$ is the volume fraction of the continuous mixer that is

231 assumed to correspond to plug-flow. The parameters defining $e(\theta)$ are the number of tanks in series and

232 the minimum and mean residence time. The mean residence time was calculated (13) whereas the number

233 of tanks and minimum residence time were estimated by minimizing the residual sum of squares (19)

234 between experimental and fitted data as described by Kumar et al. (20I5). The coefficient of determination

$235 \quad\left(R^{2}\right)$ was used to assess model performance.

236 Residual sum of squares $=\sum\left(e(\theta)_{\text {exp }}-e(\theta)_{\text {sim }}\right)^{2}$

237 One can calculate the fitted RTD using the fitted normalized RTD, $\frac{\mathrm{e}(\theta)}{\mathrm{t}_{\mathrm{m}}}=\mathrm{e}(\mathrm{t})$

\section{$238 \quad$ 4.3.5 Model based macro-mixing evaluation}

239 Axial mixing describes the transport and back mixing in the system and is characterized by estimating the 240 RTD. The design and process variables of the continuous blender must be carefully selected such that its 24I RTD has sufficient macro-mixing ability to filter out feeder fluctuations. Levenspiel (1999) illustrated one 242 can predict the concentration of the active in the outlet stream of a continuous mixer $\mathrm{C}_{\text {out }}(\mathrm{t})$. Therefore, 243 the fitted RTD and concentration of the active in the inlet stream $\left(C_{i n}\right)$ have to be determined using 244 equations 20 and 21 , respectively. Subsequently, these signals were convoluted (22) in Matlab R20I5b 245 (Mathworks, Natick, Massachusetts, USA).

247 Where $F R(t)$ is the gravimetric flow rate over time for the component specified.

249 The residual standard deviation on the tracer concentration in the outlet stream (RSD_Cout) was 250 determined as an indicator of macro-mixing performance.

\section{$25 \mathrm{I} \quad 4.3 .6$ Fill level measurement}


252 The fill level or residence mass is defined as the amount of material in the mixer. During start-up, the fill

253 level increases with time before a plateau is reached. The mixer operating under constant fill level is

254 considered to be operating at steady state conditions. The fill level in the mixer determines the residence

255 time and thus the strain experienced by the powder inside the mixer. The fill level in the blender was

256 determined by stopping the steady state process instantaneously. The powder inside the blender was then

257 collected pneumatically. In the absence of dead volumes inside the continuous mixer, fill level measurement

258 is complementary to mean residence time calculation from RTD estimation (Vanarase and Muzzio, 20II).

259

Bulk residence time $(s)=\frac{\text { Fill level }(g)}{\text { Flow rate }\left(\frac{g}{s}\right)}$

\subsubsection{Strain measurement}

In convective continuous mixers, energy input is provided by the rotating impeller. The impeller speed influences the fill level and mean residence time. Strain is thereby proportional to the product of speed and mean residence time which reflects the number of blade passes in the mixer (Vanarase et al., 20I3b).

Number of blade passes $=$ Mean residence time $(s) * \frac{\text { Impeller speed }(\mathrm{rpm})}{60}$

\subsection{Tableting}

\subsection{Experimental set-up}

The Modul S press was equipped with an overfill cam of $14 \mathrm{~mm}$ and 38 punches (euro B, $10 \mathrm{~mm}$ diameter, concave) to produce tablets with a target weight of $400 \mathrm{mg}$. The press operated in an automatic mode where the pre-compression displacement signal was used to monitor tablet weight which was controlled by adjusting fill depth. The standard paddles were installed in the forced feeder and their speeds were kept constant at 30 and $60 \mathrm{rpm}$ for the first and second paddle feeder, respectively. The turret speed was set to ensure that the theoretical flow rate of the press matched the total flow rate of the feeders. This corresponded to a speed of 27,55 and $82 \mathrm{rpm}$ for a flow rate of 25,50 and $75 \mathrm{~kg} / \mathrm{h}$, respectively. During start-up the feed tube level initiated turret rotation at its target (50\%). The turret speed was modulated during processing to maintain this target. Below $20 \%$ feed tube level, the press was stopped to allow filling of the feed tube, whereas at 100\% feed tube level the mixer and feeders were stopped. Pre-compression force was set at 15.2 MPa. The pre-compression height, i.e. the distance between the punches at precompression, was regulated with $0.01 \mathrm{~mm}$ adjustments such that a minimal pre-compression displacement of $0.1 \mathrm{~mm}$ at the rollers was maintained. The main compaction height was set at $2.252 \mathrm{~mm}$ whilst the main compression pressure was monitored. At each flow rate, tabletability, compressibility and compactibility 

$\mathrm{MPa}$.

\subsubsection{Tablet characterization}

\subsubsection{Weight variability}

285 Tablets $(n=10)$ were randomly selected from grab samples collected at an interval of $10 \mathrm{~s}$. Tablet weight 286 variability was expressed as the residual standard deviation on the tablet weight ( $R_{\text {SD }}$ w).

\subsubsection{Tablet strength and porosity}

288 Tablets $(n=20)$ were weighed and their hardness, thickness and diameter was determined (Sotax HT I0, 289 Basel, Switzerland). The tablet tensile strength (MPa) was calculated using equation 25 where $\mathrm{F}, \mathrm{d}$ and $\mathrm{T}$ 290 denote the crushing force $(\mathrm{N})$, tablet diameter $(\mathrm{mm})$ and tablet thickness $(\mathrm{mm})$, respectively.

291 Tensile strength $=\frac{2 F}{\pi d T}$

292 The porosity of the formed compacts was calculated using equation 26 where $\rho_{\text {app }}$ denotes the apparent tablet density $(\mathrm{g} / \mathrm{mL})$ which was calculated by dividing the tablet mass by its volume.

$294 \quad \varepsilon_{\text {Tablet }}=1-\frac{\rho_{\text {app }}}{\rho_{\text {true }}}$

\subsubsection{Immediate axial recovery (IAR)}

Axial recovery of tablets after ejection was calculated via equation 27 (Armstrong and Haines-Nutt, 1972):

\subsubsection{Content uniformity}

Tablets $(n=30)$ were randomly selected from a grab sample collected during steady state processing. Each tablet was homogenized in $400 \mathrm{~mL}$ phosphate buffer with a pH of 7.4 (USP monograph) using an automated tablet preparation workstation (TPW TM, Sotax, Basel, Switzerland). Subsequently, $10.0 \mathrm{~mL}$ of homogenate was filtered and the NAP content derived from the absorbance of the filtrate at $332 \mathrm{~nm}$ using a UV spectrophotometer with $0.5 \mathrm{~cm}$ cell (Agilent 8453, Agilent technologies, Santa Clara, USA). Content uniformity $(C U)$ was expressed as the residual standard deviation on the NAP content $\left(R_{S D} D_{c u}\right)$.

\subsubsection{Dissolution}

306 Dissolution tests were performed $(n=6)$ in $\mathrm{pH} 7.4$ phosphate buffer using the paddle method with sinkers

307 (USP monograph for NAP tablets). The temperature of the dissolution medium was maintained at $37 \pm$ 
$0.5^{\circ} \mathrm{C}$, while the rotation speed was set at $100 \mathrm{rpm}$. Samples of $9 \mathrm{~mL}$ were withdrawn after $0.5, \mathrm{I}, 2,4,6$,

$3098,10,12$ and $16 \mathrm{~h}$. The drug content in these samples was derived from the absorbance of the samples at

$310 \quad 332 \mathrm{~nm}$ using a UV spectrophotometer ( $\mathrm{l} \mathrm{cm}$ cells).

3II The percent drug released versus time profiles were used to investigate the mechanism of drug release

312 and evaluate the influence of process settings. The power law was used as a simple semi-empirical equation

313 (28) to describe the drug release from the polymeric systems (Siepmann and Peppas, 2012):

$314 \quad \frac{M_{t}}{M_{\infty}}=k t^{n}$

315 Where, $M_{t}$ is the amount of drug released at time $t, M_{\infty}$ is the amount of drug released after infinite time,

$316 \mathrm{k}$ is a kinetic constant incorporating structural and geometric characteristics of the tablet, and $\mathrm{n}$ is the

317 release exponent, indicative for the drug release mechanism. The model was fitted using the curve fitting

318 toolbox in Matlab R2015b. For matrix tablets, a release exponent of 0.5 indicates diffusion-controlled drug

319 release whereas 1.0 indicates erosion or swelling-controlled release. Intermediate values suggest that

320 diffusion and erosion contribute to the overall release mechanism (Levina and Rajabi-Siahboomi, 2004;

321 Siepmann and Peppas, 20I2). The time to reach $20 \%$ and $50 \%$ release were also included as responses.

\section{Results and discussion}

\section{$323 \quad$ 5.I Raw material characterization}

324 Individual materials and blends were characterized extensively to compile a multivariate dataset

325 (complementary data). Subsequently, principal component analysis was applied on this dataset (SIMCA I4).

326 The score plot was used (figure 3, left) to identify how individual materials and blends are situated with

327 respect to each other whereas the loading plot (figure 3, right) was used to reveal how variables are related

328 to each other. The score and loading plots were observed simultaneously to reveal the physical meaning

329 of these components. Materials with a specific location on the score plot have high values for variables

330 with similar position on the loading plot (positively correlated) and low values for variables at the opposite

331 side of the loading plot (negatively correlated). To evaluate a variable, one can draw a straight line through

332 the origin and project other variables of interest on that line to assess their correlation. Additionally, the

333 correlation matrix (complementary data) was used to verify their magnitude of correlation.

334 Three components were fitted in the model explaining $96 \%$ of the variation in the dataset. The first, 335 second and third component explained 74,16 and $6 \%$, respectively. The first component corresponds to 336 density-weighed flow as these variables have high positive loadings for the first component but relatively 
337 low loadings for the second component. Materials with high scores for component I flow well under

338 gravity and usually consist of larger particles. Furthermore, the different densities are correlated as they

339 cluster in the right top corner and are negatively correlated with porosity which is located in the left

340 bottom corner. Powder flow and fines are positioned in the right bottom corner of the loading plot (figure

$34 \mathrm{I} 3$, right) and are negatively correlated with cohesion (left top corner). Powder flow deteriorated when the

342 powder bed contained more fine particles due to their high cohesiveness. The variation in the dataset for

343 density, flow, cohesion and porosity is clearly described by the second principal component. However,

344 there is no single property which truly describes this second component as these variables are not

345 completely independent from the first component (i.e. density-weighed flow). The variability in

346 compressibility and cohesion of the powder bed is described by component 3 (not shown).

347 The key properties of each individual material are depicted in table I. The score plot reveals Starch I500

348 is situated in the top right corner: the powder combined easy flow with high density and flowed as a

349 consequence well under gravity. Spray dried lactose (FF3/6) combined better flow with similar density

350 which explains why its density-weighed flow was even higher. FF3 I 6 had a remarkably lower tapped density

$35 \mathrm{I}(0.7 \mathrm{Ig} / \mathrm{mL})$ compared to Starch $1500(0.80 \mathrm{~g} / \mathrm{mL})$ and has therefore lower scores for component 2. MgSt

352 is situated in the left bottom corner of the score plot due to its poor density-weighed flow ( $\mathrm{ff}_{\mathrm{p}}=0.42$ )

353 combined with its specifically low true density $(1.04 \mathrm{~g} / \mathrm{mL})$ and high porosity (0.82). Compared to MgSt,

354 NAP is situated slightly more to the right side but significantly higher along the axis of component 2. NAP

355 flows also poor under gravity $\left(\mathrm{ff}_{\mathrm{p}}=0.34\right)$ but is significantly denser. Pre-blending NAP with $\mathrm{SiO}_{2}$ improved

356 powder flow although $\mathrm{SiO}_{2}$ made the powder bed more compressible. Both HPMC grades had a unique

357 location on the score plot: low positive scores for component I and high negative scores for component

358 2. The HPMCs combine easy flow with relatively low density. The Methocel DC2 grade was plotted to the

359 right of Methocel CR grade. The direct compression grade has a higher particle size which improves

360 powder flow and reduces the cohesiveness and compressibility of the powder bed.

36I Two placebo sustained release platform formulations (section 3), composed of either Methocel CR or

362 Methocel DC2 as matrix former, were characterized to evaluate the impact of HPMC grade on blend

363 properties. The Methocel DC2 blend was positioned to the right of the Methocel CR blend on the score

364 plot. This was attributed to the improved flow (flow function coefficient of 6.80 compared to 5.75 ) and

365 slightly higher bulk density ( $0.46 \mathrm{vs} 0.44 \mathrm{~g} / \mathrm{mL})$ of the Methocel DC2 blend. Both placebo blends shifted to

366 the left on the score plot when 30\% NAP was incorporated in the formulations. The high level of NAP

367 reduced the density and deteriorated the flow. However, the Methocel DC2-based blend clearly retained

368 the most favorable blend properties as it had higher scores for component I and 2 . The score plot also

369 revealed the impact of drug load on blend properties. An increase in NAP content gradually reduced the 
density and deteriorated the flow: a drug load increase from $2 \mathrm{I}$ to $40 \%$ reduced the flow function coefficient from 2.15 to 1.53 and the bulk density from 0.41 to $0.29 \mathrm{~g} / \mathrm{mL}$.

This principal component model functions as a dynamic raw material property database that reveals in which properties materials differ. Loading new samples in the model allows to situate them among materials for which process knowledge is already established. Moreover, characterizing materials enabled correlation and modeling of their properties with process and product responses. In other words the key material properties at the loss-in-weight feeding (section 5.2), continuous blending (section 5.4 and 5.5) and tableting (section 5.5.2) unit operation could be revealed.

\subsection{Loss-in-weight feeding}

All feed factor profiles showed a similar trend: the feed factor was initially near its maximum when the hopper of the feeder was completely full (Figure 4). The feed factor remained then relatively stable during emptying until a material specific hopper fill level was reached. Subsequently the feed factor decreased gradually towards a minimal feed factor (figure 4, left). One can assume that the actual weight of the powder bed regulates the compression of powder at the screw inlet over time. The powder bed is densified as a function of the gravitational pressure exerted by its own weight. Hence the compressive pressure decreased when feeders emptied their hopper. The resulting decrease in density at the screw inlet is hypothesized to cause this feed factor decay.

The maximum feed factor was correlated with bulk density $\left(R^{2}=0.85\right)$ (figure 4 , right). Twin screws act as a pump by displacing a fixed volume, i.e. the volumetric feed factor, every screw revolution. Therefore, a higher density at the screw inlet yields theoretically a higher feed factor. This theoretically predicted feed factor-bulk density relation (calculations and assumptions described in section 4.2.2) corresponds relatively well with the experimentally derived feed factor-bulk density relation. However, flow properties clearly confounded the bulk density-feed factor correlation. Two materials deviated from the theoretical curve which indicated that bulk density is not the only property governing the transport capacity. NAP is classified as a very cohesive material and has a significantly lower feed factor compared to slightly better flowing materials with similar density (i.e. NAP+SiO2). This might be attributed due to screw layering and/or incomplete screw flight filling by NAP. In contrast, the experimentally derived feed factor of the freely flowing FF316 was lower than the theoretically predicted feed factor. As incomplete screw filling seems unlikely for FF316, the density in the screw inlet must have been significantly lower than the bulk density. It is hypothesized the powder was loosely packed in the screw because the particles flowed freely in the rotating screw instead of being transported as a packed bed. Interestingly, the maximum feed factor for Starch 1500 (2.97) was significantly higher compared to FF3 I6 (2.12). Both materials have a similar bulk 
density ( $\approx 0.63 \mathrm{~g} / \mathrm{mL}$ ) but packed significantly different (i.e. Starch 1500 has a Hauser ratio of I.29 compared to 1.13 for FF316) and flowability (i.e. Starch 1500 flow is passable and FF316 flow is good). Due to its compressibility, Starch 1500 has the ability to densify in the hopper and/or screw. In combination with its moderate flow properties, Starch 1500 will be efficiently transported as a packed bed instead of loose particles. Furthermore tapped density, compared to bulk density, generally correlated better with the maximum feed factor $\left(R^{2}=0.91\right)$. These observations underpinned that bulk density, compressibility and powder flow impact the maximum feed factor value.

Table 2 presents the feeder flow rate ranges based on a system flow rate range of 25 to $75 \mathrm{~kg} / \mathrm{h}$ and the ratio of the components in the formulation. The maximum feed factor value was used to estimate the drive command at the intended flow rates. Twin concave screws with $20 \mathrm{~mm}$ pitch appeared to be perfectly suited to dose the high throughput products FF316 and Methocel DC2. Due to its high feed factor, a relatively low drive command (3.0\%) was required to dose Starch 1500 at $2.5 \mathrm{~kg} / \mathrm{h}$. The feeder was therefore equipped with $10 \mathrm{~mm}$ pitch concave screws to enable operation at double the drive command (6.1\%) and avoid thereby pulsating mass flow. Due to its low dose in the formulation, MgSt required an extremely low mass flow $(0.125 \mathrm{~kg} / \mathrm{h})$ which inevitably resulted in an extremely low drive command $(0.5$ \%) using concave screws with $20 \mathrm{~mm}$ pitch. Hence, screws with $10 \mathrm{~mm}$ pitch were selected to enable $\mathrm{MgSt}$ dosing at higher drive command ( $1.3 \%$ ). A single feeder dosing pure NAP was not able to achieve the maximum flow rate of $22.5 \mathrm{~kg} / \mathrm{h}$. One strategy could be to set-up multiple NAP feeders in parallel. Alternatively, feeding a $\mathrm{NAP}+\mathrm{SiO}_{2}$ pre-blend at the maximum flow rate $(22.9 \mathrm{~kg} / \mathrm{h})$ required $76.4 \%$ drive command. During in-line blending trials at $75 \mathrm{~kg} / \mathrm{h}$ two $\mathrm{NAP}+\mathrm{SiO}_{2}$ feeders were eventually installed to prevent operating near the drive command limits at lower hopper fill levels.

A hopper refill strategy was derived from the normalized feed factor profiles (figure 4 , middle). The goal is to operate the feeder within a fill level window where the feed factor remains stable and close to its maximum value. Hence, less control actions are required to deal with feed factor kinetics during emptying and refilling of the hopper. The feed factor remained relatively stable till low fill levels for Starch 1500 , FF3 I 6 and HPMC: a feed factor decrease of $5 \%$ was only observed below $15 \%$ fill level. Their feeders were therefore run down to $20 \%$ fill level before triggering a refill. Highly compressible powders with low density displayed a decay at significantly higher fill level. A decay of $5 \%$ was already reached at 80,50 and $20 \%$ fill level for NAP, MgSt and $\mathrm{NAP}+\mathrm{SiO}_{2}$, respectively. The normalized feed factor profile clearly illustrated an additional advantage of dosing NAP+SiO2 pre-blend: the normalized feed factor remained constant till $40 \%$ fill level for the pre-blend whereas the decay was initiated from the start for NAP. A refill at $40 \%$ fill level was triggered for the pre-blend and MgSt. Operating in the same feed factor window with NAP would 
require more frequent refills. The actual impact of hopper refills during continuous manufacturing was further investigated at the feeding and blending unit operation (section 5.3.6).

\section{$436 \quad 5.3$ Effect of impeller configuration and speed}

437 Residence time estimation was performed as a function of impeller speed (i.e. RPM) and configuration (i.e. 438 RMB) (figure 5). Besides changes in RTD profiles, the impact of process and design parameters was clearly 439 reflected in other process and product responses. Therefore, a PLS model was fit, simultaneously 440 representing the variation of all responses to the variation and interaction of the factors. Thereby the 44I loading plot is a useful tool to understand how factors and responses are correlated (figure 6). The loading 442 plot shows that the first PLS component is dominated by the number of RMB mounted on the impeller 443 (on the negative side of the $\mathrm{X}$-axis) and to a lesser extent by impeller speed (on the positive side). The 444 second component is a combination of impeller speed and the quadratic and interaction model terms. 445 Several responses appear to be correlated: the spread of the (normalized) RTD, fill level, strain, bulk and 446 mean residence time cluster along the axis of component I on the loading plot. These responses have 447 higher values when the impeller is equipped with more RMB and operates at lower speed. Responses 448 describing the ratio of convective transport and dispersive mixing (péclet number and number of tanks) 449 showed negative correlation with this response cluster, especially with the normalized variance. Installing 450 more RMB and lowering the mixing speed improved the axial mixing efficiency (low number of péclet and 45I tanks and low variability in the outlet stream). Remarkably, the blend uniformity measures are located near 452 the origin and hence not significantly impacted by the investigated factors. Variability in tablet weight and 453 content was higher for high values of the second component indicating the importance of the quadratic 454 terms to describe their variance. Remarkably, these tablet properties did not group with RTD related 455 responses. Hence one can conclude that both RTD estimation and product quality determination were 456 required to fully characterize the manufacturing system. Effects and factor interactions are discussed in 457 more detail below using figures 7, 8, 9 and 10. The size of the effect is presented in a table below the 458 corresponding effect plot.

\section{5.3.I Powder flow behavior in the continuous mixer}

\subsection{I.I Effect on fill level, bulk residence time and mean residence time}

46I The responses fill level, bulk residence time and mean residence time spanned a wide range from 0.096 to $4620.610 \mathrm{~kg}, 24$ to $88 \mathrm{~s}$ and 97 tol $96 \mathrm{~s}$, respectively. Overall, good correlation $\left(\mathrm{R}^{2}=0.96\right)$ was observed 463 between the responses bulk residence time and mean residence time, indicating that fill level measurements 464 and RTD estimations are complementary. The NIRs probe is implemented in the feed tube of the tablet 465 press which explains the absolute difference between bulk and mean residence time. The impeller 
configuration is an important factor to include in RTD studies for continuous mixers as the impeller drives the mixing and transport of particles through the mixer. The RMB had a significant effect on fill level, bulk and mean residence time (figure 7, top). By extending the RMB section, more powder accumulated in the mixer due to more restricted material flow. For fill level and bulk residence time, this effect was not linear and intensified when more RMB were installed. The experimental error inherently associated with RTD estimation (higher error bars compared to fill level estimation) probably caused statistical insignificance of the quadratic term for mean residence time. Next to the number of RMB, the main effect of impeller speed was significant for fill level, bulk and mean residence time. This can be explained by the higher conveying rate of powder within the blender when the impeller rotates faster. The impact of speed on fill level and bulk residence time was mainly linear as the quadratic term had a statistically significant although very limited effect. The interaction effect (figure 7, bottom) of RMB and speed on fill level, bulk and mean residence time was significant. Remarkably, an increase in speed reduced the impact of the impeller configuration. At low filling conditions (i.e. for low number of RMB), marginal differences in these responses were observed when the impeller speed was varied from its low to high level. For this configuration, the conveying rate at low impeller speed was still sufficiently high to prevent an accumulation of powder in the mixing section. When the length of the mixing section is extended and the mixer operates at low speed, the powder transported by the initial conveying section is less able to pass the mixing section without undergoing restriction to flow. Consequently, the powder accumulates in the mixer under these conditions. Operating at high impeller speed level increased the conveying rate which reduced the efficiency of the shear zone to restrict powder flow. Consequently fill level, bulk and mean residence time were more reduced (figure 7).

\subsubsection{Effect on minimum residence time}

488 The lag time describes the rate of transport through the blender. Quantifying the minimum residence time is important to understand when disturbances at the feeding stage will reach the inlet of the tablet press.

490 The minimum residence ranged from 7 to $53 \mathrm{~s}$. The effect plot shows the main effects of impeller speed $49 \mathrm{I}$ and number of RMB are statistically significant in contrast to their quadratic and interaction terms (figure

492 7, top). Remarkably, the minimum residence time is the only response where speed is the most influential

493 factor. The enhanced conveying rate reduced transport time through the blender. In contrast, equipping 494 the impeller with more RMB restricted powder flow which slowed down the transport rate.

\subsection{I.3 Effect on Normalized variance}

496 Perfectly mixed-flow is described by a continuously stirred tank reactor and for such a system the spread 497 of the normalized RTD curve is equal to one. By contrast, a plug-flow reactor describes a perfectly unmixed system and under this condition the normalized variance is equal to zero (Fogler, 2006). A higher 
normalized variance indicates better axial mixing conditions. In our study, the impeller configuration and speed significantly affected the normalized variance (figure 8 , top) which ranged from 0.04 to 0.18 and suggests the flow behavior in the blender was in between mixed and plug-flow. Extending the mixing section on the impeller from 8 to 16 RMB yielded a higher normalized variance which indicates the RMBs induced dispersion. Changing speed from 200 to $400 \mathrm{rpm}$ reduced the spread of the normalized RTD indicating less dispersion occurred at higher conveying rate. The data suggest a linear effect of impeller configuration and speed as the quadratic and interaction terms were not statistically significant and limited in size (figure 8 , top). Hence the normalized RTD can be widened by combining a low impeller speed with high number of RMB (figure 8, bottom).

\subsection{I.4 Effect on Péclet number, number of tanks and plug-flow volume fraction}

As the spread of the RTD curve approaches zero, the péclet number approaches infinity indicating the extent of axial mixing is low and the mixer characteristics approach a plug-flow reactor. This regime is not favorable for continuous processing as plug-flow corresponds to low axial mixing efficiency which can result in poor dampening of instream fluctuations (Kumar et al., 20I4). The applied normalized RTD model (section 4.3.4) contained two physically significant parameters namely the plug-flow volume fraction and number of constantly stirred tank reactors in series. These allow the quantification of the plug-flow volume fraction and axial mixing efficiency, respectively. Less tanks in series corresponds to more efficient axial mixing. Figure 5 confirms good model fit was achieved using the RTD model presented in section 4.3.4 ( $\mathrm{R}^{2}$ $=0.95-0.99)$.

Impeller configuration and speed had a significant impact on axial mixing efficiency (figure 8, top). Within this investigation the number of péclet and tanks ranged from 10 to 47 and 2 to 18 , respectively. In contrast, these factors had no significant impact on the plug-flow volume fraction which indicates the impeller configuration had a similar impact on the minimum and mean residence time (figure 7 , top). The impeller configuration had the largest impact on the axial mixing efficiency. By extending the impeller configuration with $\mathrm{RMB}$, the powder undergoes relatively more dispersion than transport within the mixer. In contrast, the main effect of impeller speed is a higher péclet number and more tanks in series. Higher speed yields higher conveying rates which results in less axial mixing and more plug-flow like material transport through the mixer. A strong interaction occurred between impeller configuration and speed for the péclet number and amount of tanks in series (figure 8, bottom). Processing conditions which resulted in high blender fill levels increased the axial mixing efficiency. When the impeller is equipped with low number of RMB, axial mixing is only effective at low speed as material flow is then restricted in the mixing section more frequently. An impeller with high number of RMB subjected particles to a critical strain and homogenization 
531 force making speed less influential for the efficiency of axial mixing. Hence equipping the impeller with high

532 number of RMB is a powerful tool to maintain optimal dispersion at high impeller speed.

\section{$533 \quad$ 5.3.2 Strain}

534 The strain or number of blade passes experienced by the powder within the continuous mixer was clearly dominated by the impeller configuration (figure 9, top). Significantly more strain was applied on the powder when the number of RMB was varied from low to high. The quadratic term had a significant albeit small positive effect, indicating that extending the shear zone with more RMB gradually resulted in more blade passes. The increase in strain originates from a significant change in bulk residence time associated with higher number of RMB (section 5.3.I.I and figure 7, top). Next to impeller configuration, the main effect of impeller speed and its quadratic term had a negative impact on the applied strain (figure 9, top). In general, the number of blade passes was maximal at intermediate impeller speed (figure 9, bottom). This was previously reported by other researchers for different continuous mixers and formulations (Vanarase and Muzzio, 20II; Vanarase et al., 2013). However, an interaction occurred when a high number of RMB was combined with low impeller speed, yielding similar blade passes compared to intermediate speed (figure 9, bottom). This observation can be explained by the interaction plot of bulk residence time (figure

546 7, bottom). At low speed and high number of RMB, the maximized bulk residence time compensates for the lower speed and yields similar blade passes.

\subsubsection{Blend Uniformity}

549 Section 5.3.I described the macroscopic powder flow behavior within the continuous mixer. However, these RTDs do not capture the mixing performance. Therefore, the mixing process was monitored using in-line NIRs to determine the homogeneity of the blend stream from the mixer. The relative standard deviation on the content of NAP in the blend during steady state processing was calculated as a mixing index $\left(\mathrm{RSD}_{\mathrm{ss}}\right)$ and accounts for variability on the long and short term. Imperfections in the feed rate can introduce variability on the long term. By contrast, micro-mixing performance refers specifically to the extent of de-agglomeration and local segregation and is expressed as the NAP variability over a short time interval $\left(R_{S D}\right.$ if). This corresponds to the remaining variability in the case of ideal feeding performance (Gao et al., 20II) which can be due to incomplete micro-mixing but includes also the error of the analytical method (Vanarase et al., 2013a). This short term variability was calculated by correcting the NIR

559 predictions for drifts using the curve fitting toolbox in MATLAB (Mathworks, Natick, Massachusetts, USA).

560 Despite, the impeller speed and configuration had no statistically significant impact on both the long and 56I short term variability. This is due to the narrow ranges that were observed for these mixing indices, 0.70 -

$562 \quad 1.10 \%$ and $0.65-0.80 \%$ respectively, which indicated excellent blend uniformity during steady state 
processing. The limited difference between long and short term variability illustrated the continuous mixer had sufficient axial mixing to filter out feeder fluctuations. Additionally, the root mean squared error of prediction of the in-line NIR model was $0.24 \%$ which indicated that for a target drug load of $30 \%$ the lowest achievable RSD would be around $0.24 \% / 30 \% \approx 0.80 \%$. Hence, one can conclude the best possible mixing performance was achieved that could be detected with the employed analytical method.

\subsubsection{Tablet content uniformity}

Content uniformity ranged from $0.5 \mathrm{I}$ to $1.28 \%$ and indicated excellent micro-mixing performance. The impeller configuration had a statistically significant effect on tablet content uniformity (figure 9, top). However, this effect was nonlinear as reflected by the significant quadratic term. When the number of RMB changed from 8 to 12, tablet content variability decreased marginally. However, equipping the impeller with 16 RMB increased tablet content variability (e.g. 0.45\% difference for $200 \mathrm{rpm}$ respectively). The impeller speed had no statistically and significant influence on content uniformity when it was varied from its low to high setting. However, also for speed the quadratic term was significant indicating a curved effect (figure 9, top). The interaction plot (figure 9, bottom) confirms that optimal homogeneity could be achieved at intermediate impeller speed for a fixed impeller configuration. This can be attributed to the maximum number of blade passes which the powder experienced at intermediate speed (figure 9, bottom). However, the good correlation between content uniformity and strain for a fixed impeller configuration (e.g. $R^{2}=0.91$ for $8 \mathrm{RMB}$ ) deteriorated when data obtained from multiple impeller configurations is included $\left(R^{2}=0.45\right)$. These findings suggest that not only the number of blade passes but also the number of RMB on the impeller impacts micro-mixing and hence content uniformity.

\subsubsection{Tablet weight variability}

Tablet weight variability spanned a wide range from 2.07 to $4.77 \%$ within this design which underpinned the impact of the blending process on tablet quality. The moderate to high tablet weight variation is due to the poorly flowing Methocel CR-based formulation. The impact of improved blend properties, using Methocel DC2, on tablet weight variability is described in section 5.5.2. I. However, for the more cohesive Methocel CR-based formulation, the impeller configuration had a statistically significant influence on tablet weight variability (figure 9, top). Tablets varied more in weight when the impeller was equipped with more RMB. This impact of the impeller configuration was nonlinear and even intensified at high number of RMB. This counterintuitive observation indicated that a higher fill level, prolonged mixing time and more blade passes not necessarily resulted in improved blend properties for high speed tableting. Demixing of cohesive blends was previously described for batch blending processes and was attributed to re-agglomeration or compaction of the blend when the mixing time extended (Augsburger and Hoag, 2008). The higher levels 
of strain associated with prolonged mixing may have compacted the blend and hence deteriorated the die

596 filling consistency and resulting in a higher tablet weight variation. Also mixing speed impacted weight 597 variation in a rather complex way (figure 9, top). For an impeller equipped with 16 RMB, mixing speed had 598 only a limited impact as weight variability was mostly dominated by the impeller design. For an intermediate 599 shear zone (I2 RMB), the highest weight variability was observed when the impeller was set at intermediate 600 speed. This observation confirms that higher levels of strain can induce tablet weight variation. But 601 interestingly an interaction occurred when a high impeller speed was combined with low number of RMB 602 (figure 9, bottom) which resulted in high tablet weight variability. This observation suggests that still a 603 minimal fill level, mixing time and strain is required to achieve blend properties suitable for tableting. It is 604 clear that mixing time and strain need to be well balanced with tablet properties for the Methocel CR 605 formulation.

\subsubsection{Macro-mixing performance}

\subsubsection{Model based analysis}

A representative image of the variability on the active content in the feed stream was derived from an extended run including multiple hopper refills (figure 10, left). Hence, the practical relevance of differences in RTDs (section 5.3.I) can be evaluated by quantifying their ability to dampen both steady state flow rate deviations and perturbations introduced by hopper refill. The variability in the feed stream remained relatively low (I.07\%). The relatively high screw speed (average $\approx 290 \mathrm{rpm}$ ) eliminated pulsation and provided a fast response to perturbations, resulting in good precision (low variability) and high accuracy

6I4 (mean label claim 100.15\%). All investigated blender settings were able to sufficiently dampen the observed 615 fluctuations in the inlet stream. The label claim range (i.e. difference between maximum and minimum) in 616 the outlet stream varied from $3.46 \%$ for the lowest axial mixing condition (8 RMB at $400 \mathrm{rpm}$ ) towards $617 \quad 1.44 \%$ for the highest axial mixing condition (I6 RMB at $200 \mathrm{rpm}$ ) which is significantly lower than the 618 label claim range in the feed stream (12.7\%). The model based analysis revealed the active content 619 variability in the outlet stream ranged from 0.32 to $0.59 \%$. The effect plot (figure 10, right) shows that 620 processing with more RMB or at lower speed clearly reduced label claim variability in the blender outlet 621 stream. The loading (figure 6) and effect plots confirmed this is due to a combination of more efficient axial mixing (figure 8: higher péclet number and less tanks in series) and a higher residence time (figure 7: higher

623 bulk and mean residence time). In conclusion, the continuous blender has the proper design and process 624 ranges to filter out the noise introduced by the feeders and hence excellent macro-mixing performance was achieved.

\subsubsection{Experimental analysis}


The macro-mixing performance was experimentally verified by content uniformity analysis of grab samples collected at an interval of $10 \mathrm{~s}$ over an extended processing time (figure $\mathrm{II}$ ). Two runs were selected based on their extreme axial mixing performance: 8 RMB at $400 \mathrm{rpm}$ as low axial mixing or "lean" condition, and I 6 RMB at $200 \mathrm{rpm}$ as high axial mixing or "robust" condition. The content uniformity was 0.49 and $0.61 \%$ for the high and low axial mixing setting, respectively. The average and individual tablet content remained well within standard requirements. These findings supported our previous conclusions regarding the excellent macro-mixing performance of the system. In conclusion, uniform tablet characteristics were achieved during the steady state of the manufacturing process.

\section{$635 \quad 5.4$ Effect of drug load}

636 The NIR standards depicted in table 3 were processed using fixed settings. Changing drug load from 21.35 637 to $39.65 \%$ reduced fill level from 0.536 to $0.234 \mathrm{~kg}$ and hence also bulk residence time from 74 to $34 \mathrm{~s}$. 638 Bulk density was the key material property impacting the fill level (figure 12, left) which indicates the 639 material was transported as a dense stirred powder bed under these conditions (I6 RMB, $200 \mathrm{rpm}$ ). The 640 bulk density has been shown to be less influential when the powder bed is fluidized (e.g. at high impeller $64 \mathrm{I}$ speed) (Vanarase et al., 2013b). Blend uniformity ranged from 0.65 to $1.70 \%$ suggesting good mixing 642 performance. Despite theoretically improved product (higher density and better flow) and process (higher 643 fill level and strain) responses, a lower content resulted in less homogenous blends (figure 12, right). It is 644 hypothesized this slightly reduced mixing performance can be attributed due to more challenging micro645 mixing inherently associated with the lower drug load. Furthermore, a higher level of strain has been shown to adversely impact the distribution of the drug in the final HPMC CR product (section 5.3.3).

\subsection{Effect of HPMC grade and flow rate}

\subsection{Characterization of powder flow behavior in the continuous mixer}

\subsection{I.I Effect of HPMC grade}

650 The RTD was estimated for both Methocel DC2 and CR-based formulations at various processing 651 conditions. The mixing time was slightly higher $(+20 \mathrm{~s})$ for the Methocel DC2-based formulation when 652 low mixing speed is combined with high number of RMB. Here the higher bulk density of the Methocel 653 DC2 formulation extended residence time within the mixer. This corresponds well with the previously 654 described (section 5.4) density-fill level relation and confirms the powder bed is in a dense regime under 655 these conditions. Furthermore, powder flow was in this regime best described by 2 tanks for both 656 formulations indicating the ratio of mixing and transport remained unaffected (figure 13, a). However when 657 the impeller was equipped with less RMB and/or operated at higher speed, considerably more tanks were 
required to fit RTDs of the Methocel CR formulation compared to DC2 (figure 13, a). This indicated that convective transport dominated over dispersive transport for the more cohesive Methocel CR formulation under such conditions. The interaction between material properties and process parameters govern the particle-particle dissipation rate and hence the powder flow behavior within the mixer. Overall, the axial mixing efficiency was more robust to process changes for Methocel DC2 compared to CR.

\subsection{I.2 Effect of flow rate}

Processing the Methocel DC2-based formulation at higher flow rates increased the steady state fill level of the blender (figure 14, left). The bulk residence time (figure 14, middle) and strain (figure 14, right) decreased from $|3|$ to $45 \mathrm{~s}$ and 412 to 170 revolutions when flow rate increased from 25 to $75 \mathrm{~kg} / \mathrm{h}$, respectively. Although the difference in responses leveled off slightly between 50 and $75 \mathrm{~kg} / \mathrm{h}$, the mixer did not yet reach its maximum fill level. The mixer could fill up more when the flow rate is set beyond the investigated limit. However, the tablet press had a maximum capacity of $91 \mathrm{~kg} / \mathrm{h}$ for this formulation, hence the practical operational boundaries were covered within this study.

\subsubsection{Tablet quality}

\subsubsection{Tablet weight variability}

Figure I $3 \mathrm{~b}$ shows tablet weight variability is overall significantly lower when Methocel DC2 is used a matrix former (1.44 - 1.79\%) compared to CR (2.07-4.77\%). This can be attributed to the better flow of the DC2 grade which yielded improved blend properties even at high drug load (section 5.I). The latter resulted eventually in more consistent die filling and lower weight variability. Moreover, the Methocel DC2 formulation was more robust to changes in process and design variables. Figure $13 \mathrm{~b}$ clearly shows that the mixer speed and configuration had only a marginal impact on tablet weight variability using the DC2 grade. This is an advantage compared to the Methocel CR formulation where low tablet weight variability (section 5.3.5) was only achieved at specific settings where other responses (e.g. axial mixing) were less optimal. It is hypothesized that the better flowing Methocel DC2 formulation is not prone to demixing or compaction phenomena during blending at high fill levels and hence die filling was more consistent. Furthermore, weight variability remained comparable whilst operating at a flow rate of 25 (1.61\%), 50 (1.50\%) and 75 (I.72\%) $\mathrm{kg} / \mathrm{h}$. Despite the high drug load, the Methocel DC2 formulation flowed sufficiently for high speed tableting. These findings illustrated that selecting appropriate excipient characteristics can enable continuous direct compression of poorly flowing, low density APIs formulated at high drug load.

\subsubsection{Tablet content uniformity}

Although tablets with excellent uniformity could be manufactured using both formulations, the active content for the Methocel DC2 formulation was more uniform and significantly more robust (figure 13c). 
Furthermore, content uniformity for the DC2 grade remained excellent when the flow rate was increased to $50(0.74 \%)$ and $75(0.71 \%) \mathrm{kg} / \mathrm{h}$. Apparently, the micro-mixing performance was not significantly impacted by flow rate despite the reduced strain and residence time (section 5.5.1.2).

\subsubsection{Tabletability, compressibility, compactibility and axial recovery}

694 Tabletability describes tensile strength as a function of applied compaction pressure (Patel et al., 2006).

695 Tablets were stronger when compressed at higher pressures (figure 15, a). The steep increase in strength 696 in the low pressure region is due to reduced tablet porosity upon particle rearrangements and volume 697 reduction, resulting in more bonding area. More immediate axial recovery was observed at higher 698 compaction pressures (figure 15, b) as the porosity was already reduced and a further increase of pressure 699 induced elastic deformation of particles. Elastic recovery occurred after compression thereby weakening interparticulate bonding (Sun and Grant, 200I). Consequently, the tabletability curve gradually leveled off.

70I Formulations with Methocel $\mathrm{CR}$ as matrix former showed superior compaction behavior compared to

702 Methocel DC2. It is hypothesized that the smaller particles of the CR grade resulted in a higher packing 703 density and more contact points between particles, thereby improving inter-particle bonding and yielding 704 a better tabletability (Sun and Himmelspach, 2006; Thoorens et al., 2014). Tablet strength is determined 705 by bonding area and bonding strength per unit bonding area. Contributions from each of these factors 706 cannot be separated by means of the tabletability curves. Therefore the compressibility and compactibility 707 was evaluated in order to understand the observed differences in tableting behavior. Compressibility is the 708 ability of a material to undergo volume reduction as a result of an applied pressure, whereas compactibility 709 normalizes tablet strength by porosity. The Methocel CR-based formulation exhibited more 710 compressibility compared to the Methocel DC2 formulation processed at the same flow rate (figure 15, $7 \mathrm{II}$ c). At the same compaction pressures, tablet porosity was consistently lower which is correlated to a 712 higher bonding area within a tablet. For all profiles, the tensile strength was negatively correlated with 713 porosity (figure. 15, d). Although Methocel CR-based formulations exhibited a better tabletability, its 714 compactibility curve partially overlapped the Methocel DC2 curve. This observation suggested that its 715 greater compressibility is at the origin of the better tabletability of Methocel DC2. Therefore, the superior 716 tabletability is a result of its greater bonding area and not of its greater bonding strength per unit bonding 717 area.

718 Another observation is the strain rate sensitivity of the Methocel DC2 formulation: a change in flow rate 719 from 25 to $75 \mathrm{~kg} / \mathrm{h}$ yielded weaker tablets when the compaction pressure remained constant. In a 720 continuous process, increasing the flow rate affected each unit operation. Operating at higher flow rate 721 reduced RTD and strain in the continuous blenders and tablet press feed frame. As a result the lubricant 
mixing time is reduced which potentially improved tabletability. Also the dwell time during main compression decreased from 15.90 to 5.30 ms at higher flow rate as the turret needed to rotate at higher speed (27 to $82 \mathrm{rpm}$ ) to maintain the correct mass balance. As some deformation processes are time dependent, a prolonged dwell time results in more plastic deformation, leading to more consolidation. In this case, the net effect of the longer lubrication and prolonged dwell time improved tabletability, indicating that the reduced dwell time is the dominating factor for the observed strain rate sensitivity. Tablets compacted with longer dwell time showed improved compressibility. As plastic deformation is time dependent, the volume reduction and hence increase in bonding area is more important when dwell time was longer. In addition, the overlapping compactibility profiles indicated that bonding strength per unit bonding area was not significantly influenced by dwell time. Studying tabletability, compressibility and compactibility profiles highlighted the importance of porosity. One can manufacture tablets with similar tensile strength by targeting equal tablet porosity.

\subsubsection{Drug release}

735 The impact of compaction pressure and flow rate on drug release from Methocel DC2-based formulation 736 was investigated by means of a two level full factorial screening design. Figure 16 shows drug release over $737 \quad 16 \mathrm{~h}$ and the fit of the applied model. To elucidate which tablet properties steer the dissolution rate, the responses derived from the dissolution profiles (section 4.4.2.5) and their corresponding tablet properties (section 4.4.2.2) were both included. A PLS model was fit: the loading plot (figure 5.17) revealed the experimental responses clustered. This indicates the time to reach 20 and $50 \%$ drug release was highly correlated $\left(R^{2}=0.99\right)$. Interestingly, the release exponent of the dissolution model co-varied with these experimental responses $\left(R^{2}=0.95-0.98\right)$. By contrast, the kinetic constant of the dissolution model lies on the opposite side of the straight line that connects the origin with the cluster of dissolution responses. This indicates the kinetic constant is negatively correlated with the release exponent $\left(R^{2}=-0.99\right)$ and the time to reach $20\left(R^{2}=-0.99\right)$ and $50 \%\left(R^{2}=-0.97\right)$ drug release. The high correlation between experimental and model based dissolution responses indicated that the power law model was adequate to describe drug release. Moreover, the experimental and simulated dissolution data correlated well $\left(R^{2}>0.99\right)$ and confirmed the suitability of the model. The release exponent ranged between 0.46 and $0.5 \mathrm{I}$, indicating diffusion-controlled drug release.

750 The experimental design revealed that compaction pressure significantly affected dissolution responses and 751 tablet properties. Levina and Rajabi-Siahboomi (2004) described that the sensitivity of drug release to 752 compaction pressure depended upon the compressibility of the formulation: in matrices with lower 753 porosity the water uptake and water front movement was slower, which reduced the drug release rate. 754 Also in the current study, drug release was significantly slower at higher compaction pressure which was 
reflected by lower values for the kinetic constant but higher values for release exponent and a prolonged time to reach 20 and 50\% time drug release. Compacting at higher pressure reduced tablet thickness, area and porosity, whereas tablet strength and hardness improved. These observations combined resulted in a slower drug release. Based on their correlation with dissolution responses, the importance of tablet properties could be ranked from high to low as: tablet area, thickness, tensile strength, hardness and porosity. Tablet area was previously reported to steer the release rate (Li et al., 2005) and hence thickness was a simple tablet property that correlated well with all dissolution responses $\left(R^{2}: 0.90\right.$ to 0.95$)$. Ensuring low thickness variation during manufacturing of sustained release tablets is hence crucial.

763 The rate of drug release was relatively slow as the cumulative release was limited to about $60 \%$ after $16 \mathrm{~h}$.

764 One of the research goals was to elucidate the impact of HPMC grade on tablet properties. To this extent, a high percentage of HPMC was selected in the model formulation to evoke potential differences in blend and tablet properties. This relatively low drug-to-polymer ratio extended the drug release (Li et al., 2005). Altering the ratio of tablet surface area and weight was a simple tool to accelerate drug release: $80 \%$ drug was released after $16 \mathrm{~h}$ when this ratio increased with only 14\%. Future work can focus on steering the rate of drug release from continuously produced matrix tablets by modifying the ratio and physico-chemical properties of HPMC and fillers (Levina and Rajabi-Siahboomi, 2004).

\section{Conclusions}

This study presented a framework for process and product development on a continuous direct compression platform. The ability to continuously manufacture sustained release tablets was explored using a formulation with high drug load of a poorly flowing low density API. Each unit operation was thoroughly investigated to reveal how design aspects, process settings and material properties impacted the process behavior and product quality. Two HPMC matrices were evaluated: standard Methocel CR and direct compressible DC2. Characterization revealed the DC2 grade flowed better than CR and yielded eventually improved blend properties. The capacity of feeding correlated directly with the density of the materials. Determining the feed factor and flow rate requirement allowed to estimate drive command which rationalized the selection of screw pitch. Most materials showed a limited feed factor decay and were emptied till $20 \%$ fill level before triggering a refill. By contrast, more compressible powders initiated the decay at higher fill levels and were as a consequence refilled at $40 \%$ fill level. Inline NIRs was shown to be an adequate tool for RTD estimation and process monitoring. The blender possessed good macromixing capabilities as NIRs suggested excellent blend uniformity during steady state processing. The modelbased analysis of macro-mixing performance confirmed the RTD was able to dampen the observed feeder fluctuations. In addition, the excellent mixing performance was confirmed experimentally by analyzing the 
content of tablets sampled over an extended sampling time. The experimental design with Methocel CR revealed the impeller configuration had a significant impact on the powder flow within the mixer. Extending the shear zone restricted powder transport and enhanced dispersion which resulted in a higher residence time and fill level, yielding thereby more strain and optimal axial mixing efficiency. The effect of speed on mixing and transport of powder was more pronounced at high filling degree. Higher conveying rates shifted

792 RTD curves to the left, while fill level, strain and axial mixing efficiency were reduced. Furthermore, bulk

793 density was a key blend property during as a higher density resulted in a higher fill level during blending.

794 Using Methocel CR, the axial mixing and strain needed to be well balanced with tablet properties. Tablet 795 quality deteriorated when more axial mixing was achieved through extending the shear zone on the 796 impeller. However an impeller with small shear zone achieved optimal tablets with low weight and content 797 variability when the applied strain was maximized via the impeller speed. A higher robustness to changes 798 in the blending process was achieved with Methocel DC2. The better flow of the Methocel DC2 blend 799 yielded overall lower tablet weight and content variability and enabled manufacturing at $75 \mathrm{~kg} / \mathrm{h}$. This 800 observation underpinned the importance of flow during continuous blending and die-filling. Blends with 801 Methocel CR showed better tabletability driven by a higher compressibility that originates from its higher 802 bonding area. However, tablets of similar strength could be produced with Methocel DC2 by targeting 803 equal porosity. Controlling thickness during continuous manufacturing of sustained release tablets 804 appeared to be crucial. 
805

806

807

808

809

810

811

812

813

814

815

816

817

818

819

820

821

822

823

824

825

826

827

828

829

830

831

832

\section{References}

Armstrong, N.A., Haines-Nutt, R.F., 1972. Elastic recovery and surface area changes incompacted powder systems. J. Pharm. Pharmacol. 24, 135-136.

Augsburger, L.L., Hoag, S.W., 2008. Pharmaceutical dosage forms - Tablets, Third. ed.

Cartwright, J.J., Robertson, J., D’Haene, D., Burke, M.D., Hennenkamp, J.R., 2013. Twin screw wet granulation: Loss in weight feeding of a poorly flowing active pharmaceutical ingredient. Powder Technol. 238, II6-121. doi:10.1016/j.powtec.2012.04.034

Engisch, W., Muzzio, F., 2015. Using Residence Time Distributions (RTDs) to Address the Traceability of Raw Materials in Continuous Pharmaceutical Manufacturing. J. Pharm. Innov. II, 64-8I. doi: $10.1007 / s$ | 2247-0I5-9238-I

Engisch, W.E., Muzzio, F.J., 2015. Feedrate deviations caused by hopper refill of loss-in-weight feeders. Powder Technol. 283, 389-400. doi:10.1016/j.powtec.2015.06.00I

Engisch, W.E., Muzzio, F.J., 2014. Loss-in-Weight Feeding Trials Case Study: Pharmaceutical Formulation. J. Pharm. Innov. 10, 56-75. doi: 10.1007/s 12247-014-9206-I

Engisch, W.E., Muzzio, F.J., 2012. Method for characterization of loss-in-weight feeder equipment. Powder Technol. 228, 395-403. doi:10.1016/j.powtec.2012.05.058

Ervasti, T., Simonaho, S.-P., Ketolainen, J., Forsberg, P., Fransson, M., Wikström, H., Folestad, S., Lakio, S., Tajarobi, P., Abrahmsén-Alami, S., 2015. Continuous manufacturing of extended release tablets via powder mixing and direct compression. Int. J. Pharm. 495, 290-30I. doi:10.1016/j.ijpharm.2015.08.077

Fogler, S., 2006. Elements Of Chemical Reaction Engineering., Fourth. ed. Pearson international.

Fonteyne, M., Vercruysse, J., De Leersnyder, F., Van Snick, B., Vervaet, C., Remon, J.P., De Beer, T., 2015. Process Analytical Technology for continuous manufacturing of solid-dosage forms. TrAC Trends Anal. Chem. 67, 159-166. doi:10.1016/j.trac.2015.01.011

Gao, Y., Vanarase, A., Muzzio, F., lerapetritou, M., 20II. Characterizing continuous powder mixing using residence time distribution. Chem. Eng. Sci. 66, 417-425. doi:10.1016/j.ces.2010.10.045

Järvinen, K., Hoehe, W., Järvinen, M., Poutiainen, S., Juuti, M., Borchert, S., 20I3. In-line monitoring of the drug content of powder mixtures and tablets by near-infrared spectroscopy during the continuous 
direct compression tableting process. Eur. J. Pharm. Sci. 48, 680-8. doi:I0.I0I6/j.ejps.20I2.I2.032

834

835

836

837

838

839

840

841

842

843

844

845

846

847

848

849

850

851

852

853

854

855

856

857

858

859

860

Järvinen, M.A., Paaso, J., Paavola, M., Leiviskä, K., Juuti, M., Muzzio, F., Järvinen, K., 2013. Continuous direct tablet compression: effects of impeller rotation rate, total feed rate and drug content on the tablet properties and drug release. Drug Dev. Ind. Pharm. 39, I802-8. doi:10.3 109/03639045.2012.73868।

Kuentz, M., Leuenberger, H., 1999. Pressure susceptibility of polymer tablets as a critical property: a modified Heckel equation. J. Pharm. Sci. 88, 174-9. doi:10.1021/js980369a

Kumar, A., Vercruysse, J., Toiviainen, M., Panouillot, P.-E., Juuti, M., Vanhoorne, V., Vervaet, C., Remon, J.P., Gernaey, K. V, De Beer, T., Nopens, I., 20I4. Mixing and transport during pharmaceutical twinscrew wet granulation: experimental analysis via chemical imaging. Eur. J. Pharm. Biopharm. Off. J. Arbeitsgemeinschaft für Pharm. Verfahrenstechnik e.V 87, 279-89. doi:10.1016/j.ejpb.2014.04.004

Kumar, A., Vercruysse, J., Vanhoorne, V., Toiviainen, M., Panouillot, P.-E., Juuti, M., Vervaet, C., Remon, J.P., Gernaey, K. V, De Beer, T., Nopens, I., 2015. Conceptual framework for model-based analysis of residence time distribution in twin-screw granulation. Eur. J. Pharm. Sci. 7I, 25-34. doi:10.1016/j.ejps.2015.02.004

Levenspiel, O., 1999. Chemical reaction engineering, Third. ed.

Levina, M., Rajabi-Siahboomi, A.R., 2004. The influence of excipients on drug release from hydroxypropyl methylcellulose matrices. J. Pharm. Sci. 93, 2746-54. doi:10.1002/jps.2018I

Li, C.L., Martini, L.G., Ford, J.L., Roberts, M., 2005. The use of hypromellose in oral drug delivery. J. Pharm. Pharmacol. 57, 533-46. doi:10.1211/0022357055957

Meier, R., Thommes, M., Rasenack, N., Moll, K.-P., Krumme, M., Kleinebudde, P., 2016. Granule size distributions after twin-screw granulation - do not forget the feeding systems. Eur. J. Pharm. Biopharm. doi:10.1016/j.ejpb.2016.05.011

Patel, S., Kaushal, A.M., Bansal, A.K., 2006. Compression physics in the formulation development of tablets. Crit. Rev. Ther. Drug Carrier Syst. 23, I-65.

Peeters, E., 2015. Investigation of the tableting proces in continuous production: influence of feeding and extended dwell time during compression on dependent process variables and tablet properties. Ghent University.

Pernenkil, L., Cooney, C.L., 2006. A review on the continuous blending of powders. Chem. Eng. Sci. 6I, 
Portillo, P.M., lerapetritou, M.G., Muzzio, F.J., 2008. Characterization of continuous convective powder mixing processes. Powder Technol. 182, 368-378. doi:10.1016/j.powtec.2007.06.024

Siepmann, J., Peppas, N.A., 2012. Modeling of drug release from delivery systems based on hydroxypropyl methylcellulose (HPMC). Adv. Drug Deliv. Rev. 64, 163-174. doi:10.1016/j.addr.2012.09.028

Simonaho, S.-P., Ketolainen, J., Ervasti, T., Toiviainen, M., Korhonen, O., 2016. Continuous manufacturing of tablets with PROMIS-line - Introduction and case studies from continuous feeding, blending and tableting. Eur. J. Pharm. Sci. doi:10.1016/j.ejps.2016.02.006

Sun, C., Grant, D.J.W., n.d. Influence of Crystal Structure on the Tableting Properties of Sulfamerazine Polymorphs. Pharm. Res. 18, 274-280. doi:10.1023/A:I0II038526805

Sun, C.C., Himmelspach, M.W., 2006. Reduced tabletability of roller compacted granules as a result of granule size enlargement. J. Pharm. Sci. 95, 200-6. doi:10.1002/jps.2053।

Thoorens, G., Krier, F., Leclercq, B., Carlin, B., Evrard, B., 20I4. Microcrystalline cellulose, a direct compression binder in a quality by design environment--a review. Int. J. Pharm. 473, 64-72. doi:10.1016/j.jijpharm.2014.06.055

Vanarase, A.U., Alcalà, M., Jerez Rozo, J.I., Muzzio, F.J., Romañach, R.J., 20 I0. Real-time monitoring of drug concentration in a continuous powder mixing process using NIR spectroscopy. Chem. Eng. Sci. 65, 5728-5733. doi:10.1016/j.ces.2010.01.036

Vanarase, A.U., Järvinen, M., Paaso, J., Muzzio, F.J., 20I3a. Development of a methodology to estimate error in the on-line measurements of blend uniformity in a continuous powder mixing process. Powder Technol. 24I, 263-27I. doi:10.1016/j.powtec.2013.02.012

Vanarase, A.U., Muzzio, F.J., 20I I. Effect of operating conditions and design parameters in a continuous powder mixer. Powder Technol. 208, 26-36. doi:10.1016/j.powtec.2010.11.038

Vanarase, A.U., Osorio, J.G., Muzzio, F.J., 20I3b. Effects of powder flow properties and shear environment on the performance of continuous mixing of pharmaceutical powders. Powder Technol. 246, 63-72. doi:10.1016/j.powtec.2013.05.002 Vervaet, C., 2013. Stability and repeatability of a continuous twin screw granulation and drying system. 
Eur. J. Pharm. Biopharm. Off. J. Arbeitsgemeinschaft für Pharm. Verfahrenstechnik e.V 85, I03I-8. doi:10.1016/j.ejpb.2013.05.002

89I Yu, L.X., Amidon, G., Khan, M.A., Hoag, S.W., Polli, J., Raju, G.K., Woodcock, J., 2014. Understanding 892 pharmaceutical quality by design. AAPS J. 16, 77I-83. doi: I0.1208/s I2248-0 I4-9598-3

893

\section{Acknowledgements}

895 The authors are grateful to Ms. Liesa Pollet of Ghent University and Mr. Tim Derr and Mr. Scott Vass of

896 Colorcon Inc. for their many hours of analytical work in support of this project. Ivan Bogaerts, Marc

897 Lattem, Alexander Schaepman and Tomas Vermeire (GEA APC pharma solids) are acknowledged for 898 providing access and technical support on the GEA CDC-50. 


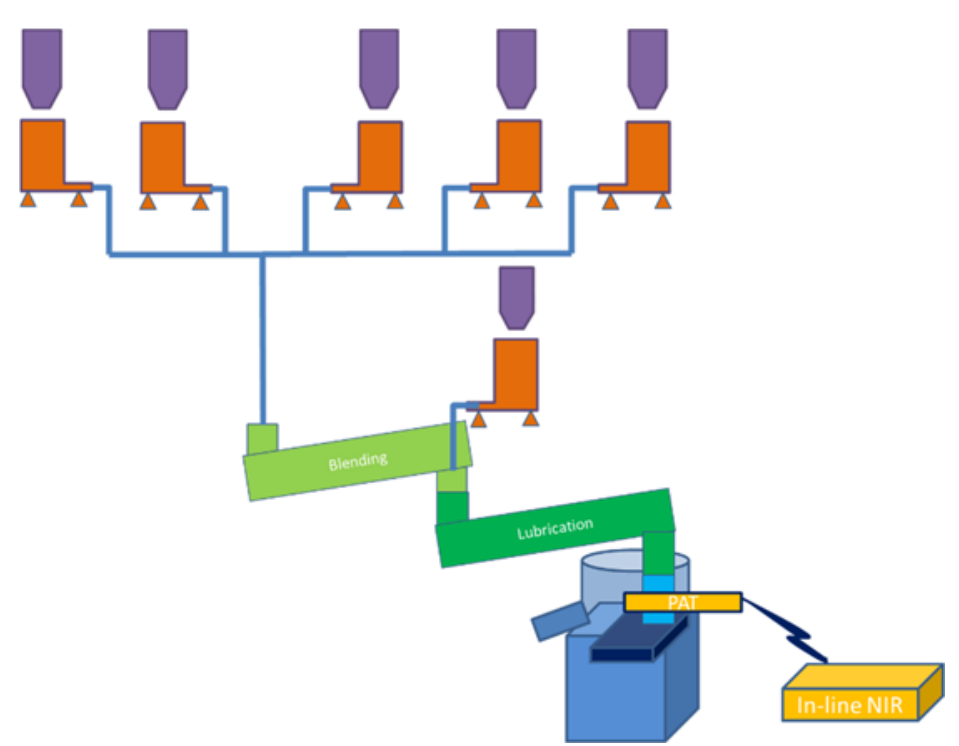

Figure I: Flowsheet of CDC-50. Powder supply and refill mechanism ( $\square$ ), twin screw feeding ( $\square$ ), blending $(\square)$, lubrication $(\square)$, feed tube $(\square)$, in-line NIRs as PAT tool $(\square)$ and tablet press $(\square)$. 


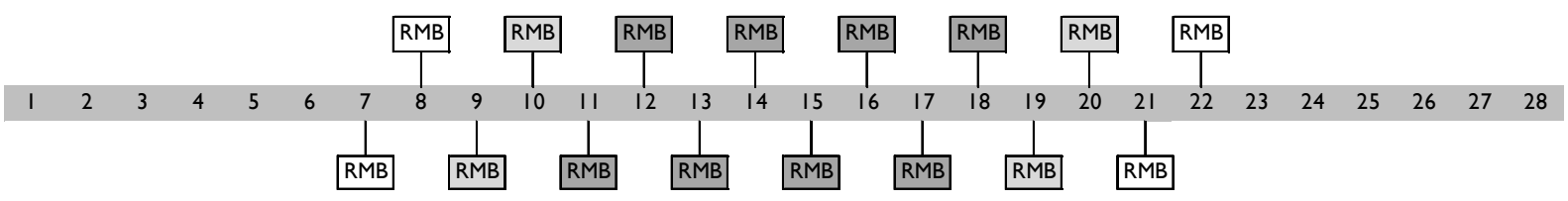

Figure 2: Schematic presentation of an impeller equipped with 8 RMB (RMB $)$ and extensions to 12 (RMB ) and 16 ( $\mathrm{RMB})$ RMB. The RMB were centered on the impeller whereas remaining blades were positioned in full transport orientation. 

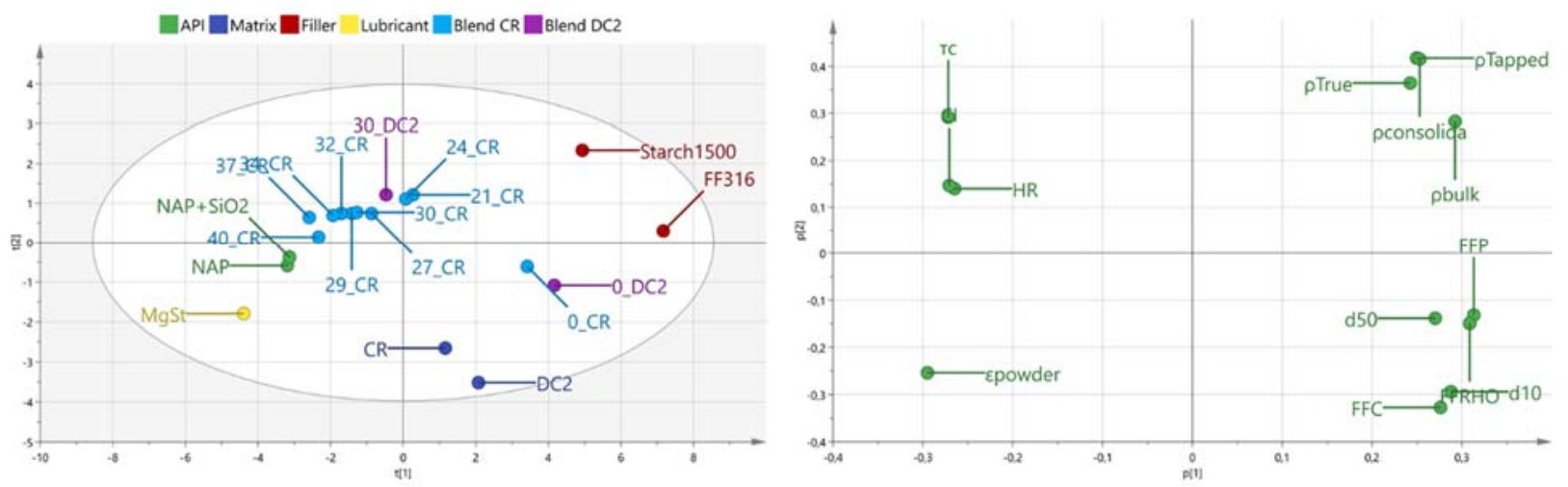

Figure 3: Scores (left) and loadings plot (right) of PCA model describing material properties. Observations on score plot are colored according to their functionality and blends are labeled according to $\mathrm{NAP}+\mathrm{SiO}_{2}$ content and $\mathrm{HPMC}$ grade. The abbreviations of properties on the loading plot are described in methods section. 

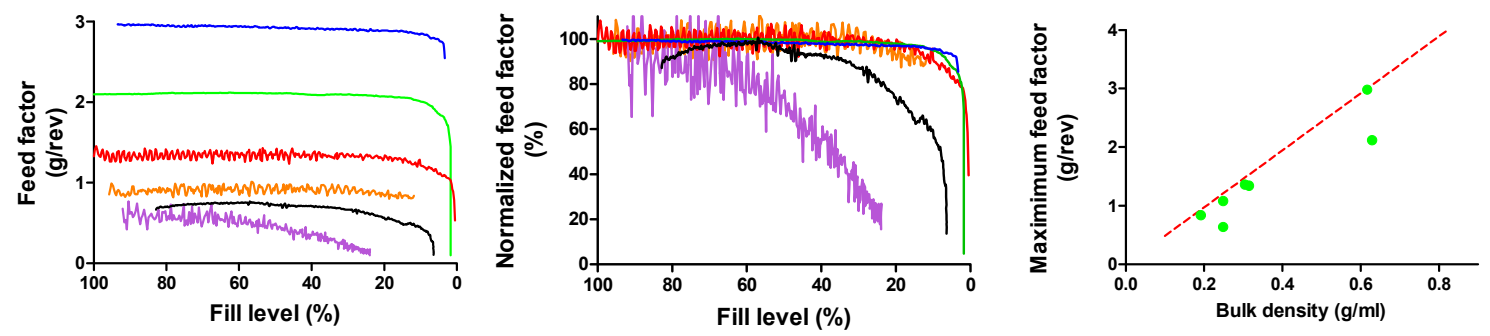

Figure 4: Feed factor (left) and normalized feed factor (middle) decay as a function of hopper fill level (\%) using concave screws with $20 \mathrm{~mm}$ pitch. Starch $1500(-)$, FF3 I6 (-), Methocel $\mathrm{DC2}(-)$, NAP+SiO2 $(-), \mathrm{MgSt}(-)$ and NAP (-). Right: theoretical (- - -) and experimental $(\bullet)$ density-feed factor relation. 
Impeller speed: 200 rpm

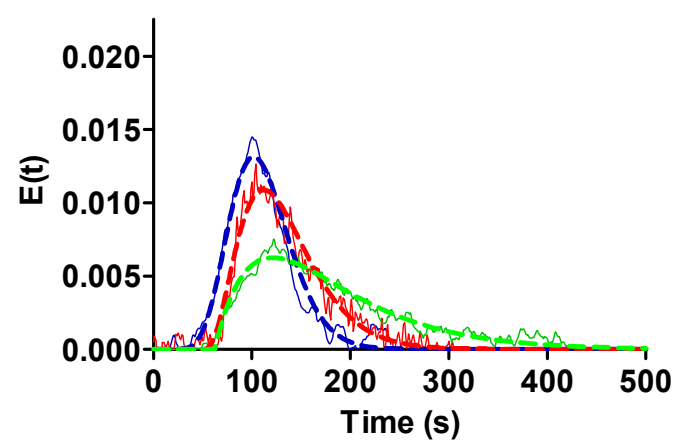

Impeller speed: $400 \mathrm{rpm}$

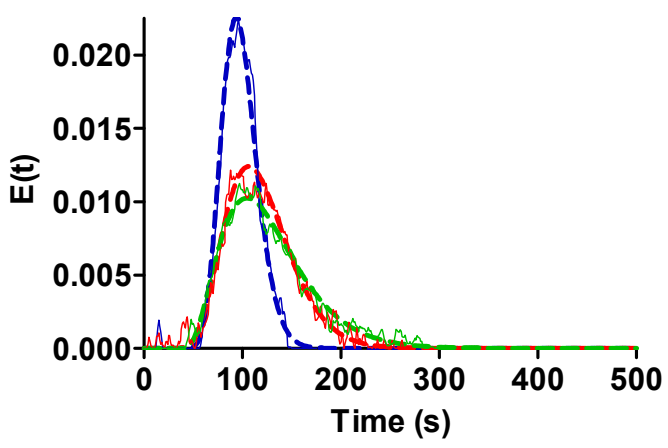

Figure. 5: Experimental RTD (-) and model fit (---) using tanks in series with plug-flow volume fraction model. Impeller equipped with 8 (---), 12 (---) and 16 (---) RMB operating at 200 (left) and 400 (right) rpm. 


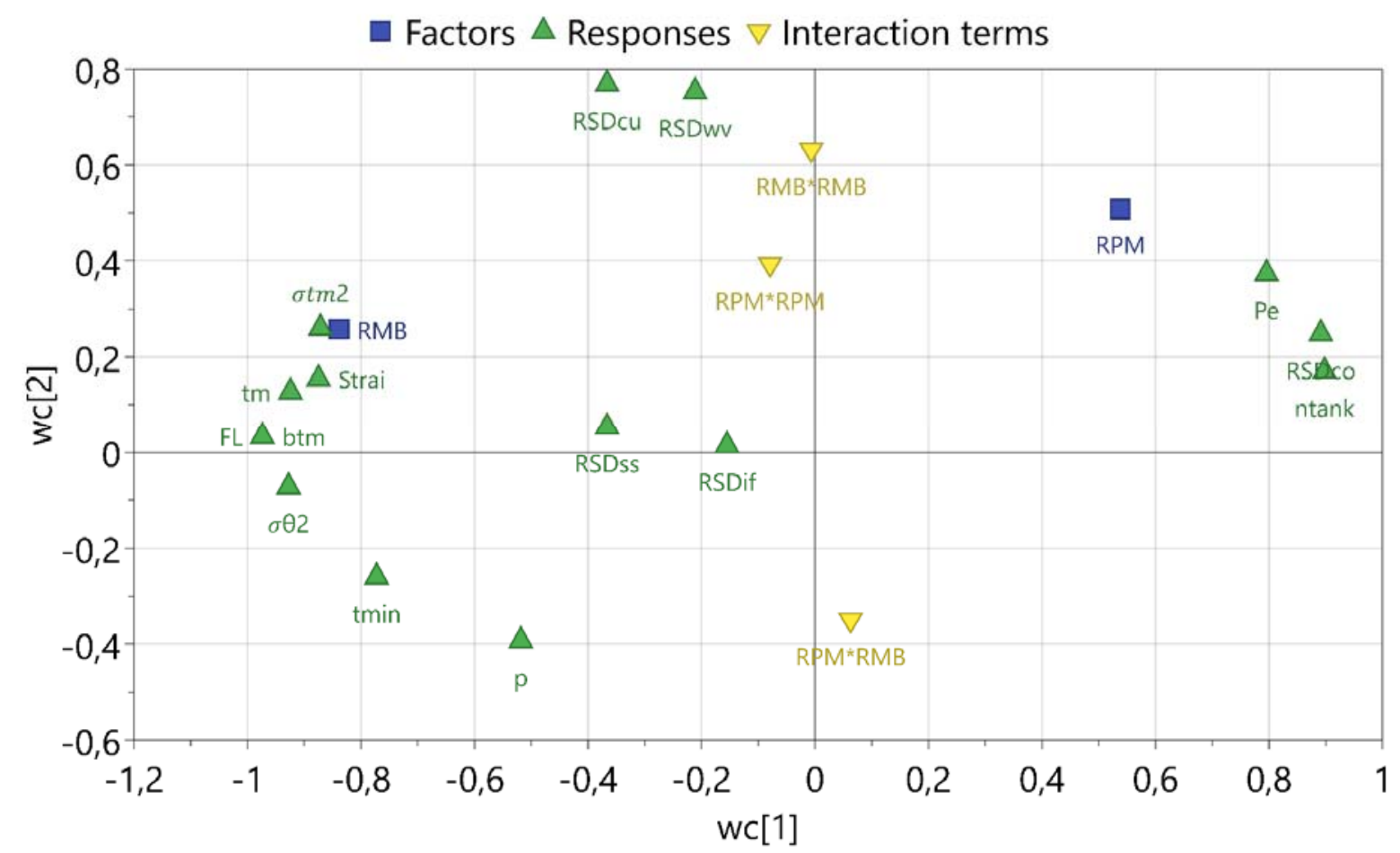

Figure 6: Blending DOE: loading plot of PLS model. RMB and RPM denote impeller configuration and impeller speed. The responses corresponding to the abbreviations are described below and ranked according to their $\mathrm{R}^{2}$ : Fill level $=1.00(\mathrm{FL})$, bulk residence time $=1.00(\mathrm{btm})$, strain or number of blade passes $=1.00$ (Strai), number of tanks in series $=0.96\left(n_{\text {tanks }}\right)$, model based macro-mixing performance or RSD_Cout $=0.93(\mathrm{RSDco})$, Péclet $=0.92(\mathrm{Pe})$, mean residence time $=0.92(\mathrm{tm})$, variance $=0.9 \mathrm{I}$ $\left(\sigma_{t m^{2}}\right)$, normalized variance $=0.90\left(\sigma_{\theta}^{2}\right)$, tablet content uniformity $=0.88\left(\mathrm{RSD}_{\mathrm{cu}}\right)$, tablet weight variation $=0.84\left(R S D_{w v}\right)$, minimum residence time $=0.78(\mathrm{tmin})$, plug-flow volume fraction $=0.56(\mathrm{P})$, short term blend uniformity $=0.54\left(R^{2} D_{i f}\right)$, steady state blend uniformity $=0.38\left(R^{2} D_{s s}\right)$. 

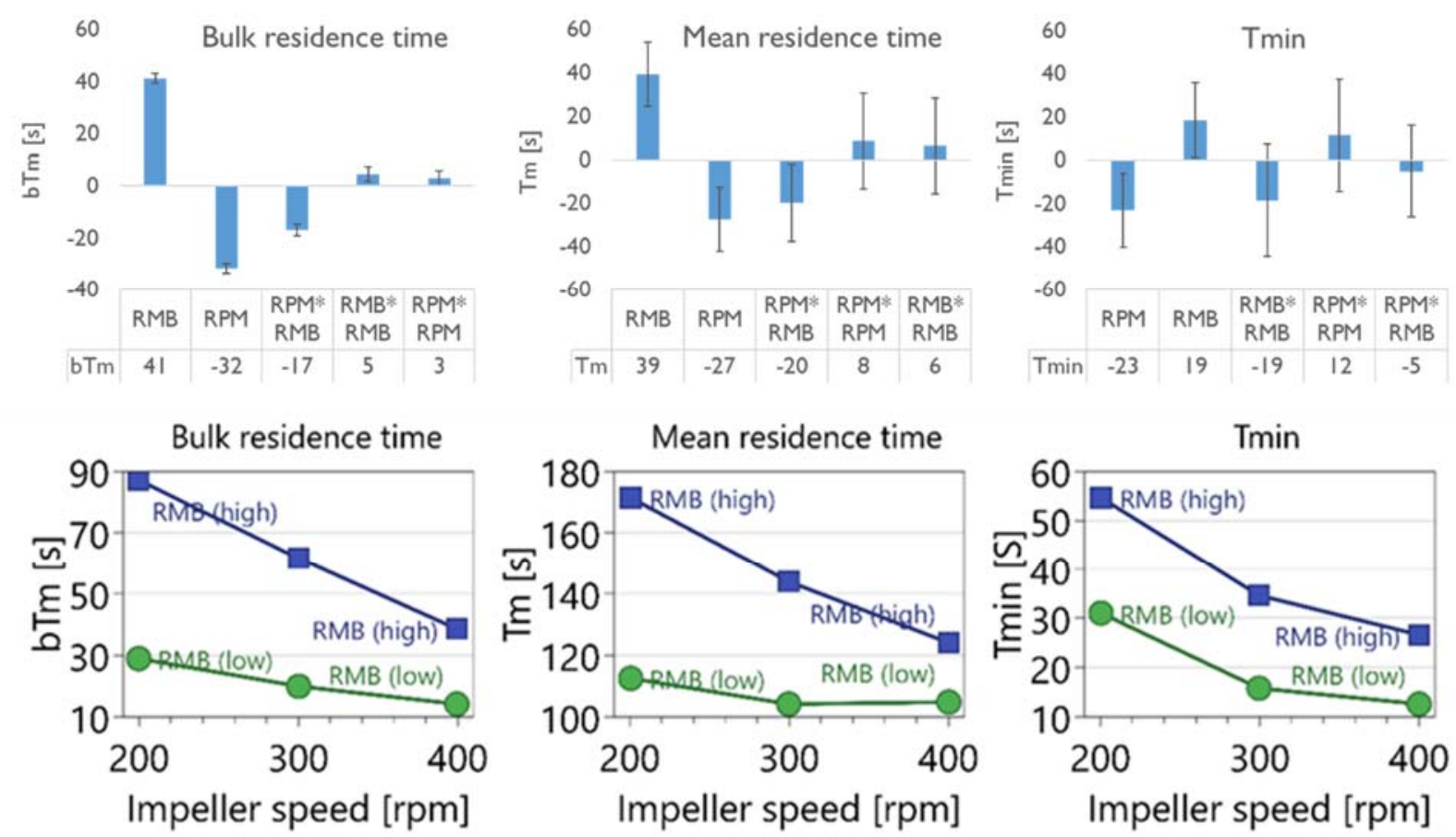

Figure 7: Blending DOE: effect (above) and interaction (below) plot for responses bulk residence time (left), mean $\left(t_{m}\right.$, middle) and minimum time ( $t_{\text {min }}$, right). The table presents the size of the effect. 

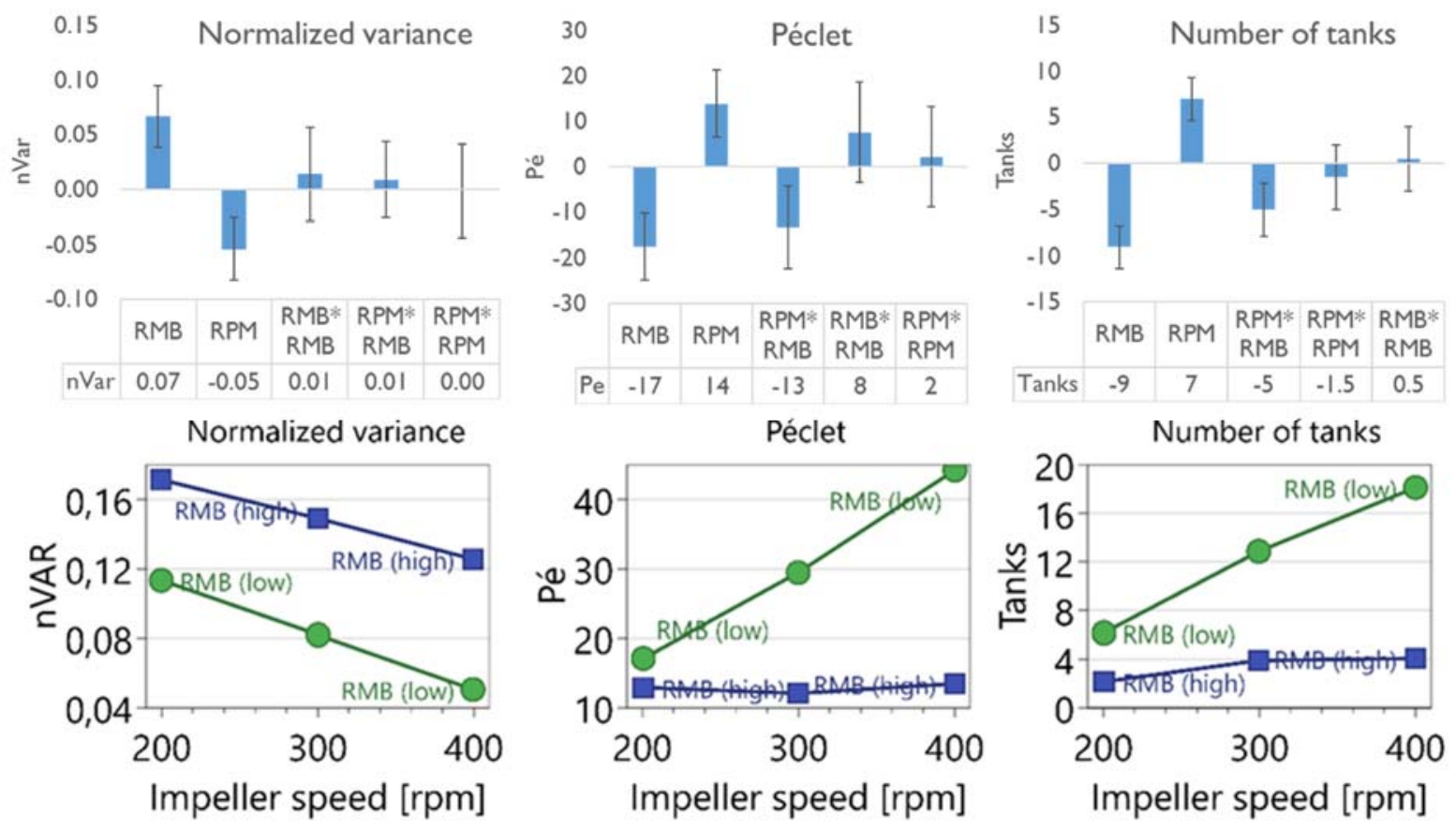

Figure 8: Blending DOE: effect (above) and interaction (below) plot for responses normalized variance $\left(\sigma_{\theta}{ }^{2}\right.$, left), peclet (Pé, middle) and number of tanks ( $n_{\text {tanks }}$, right). The table presents the size of the effect. 

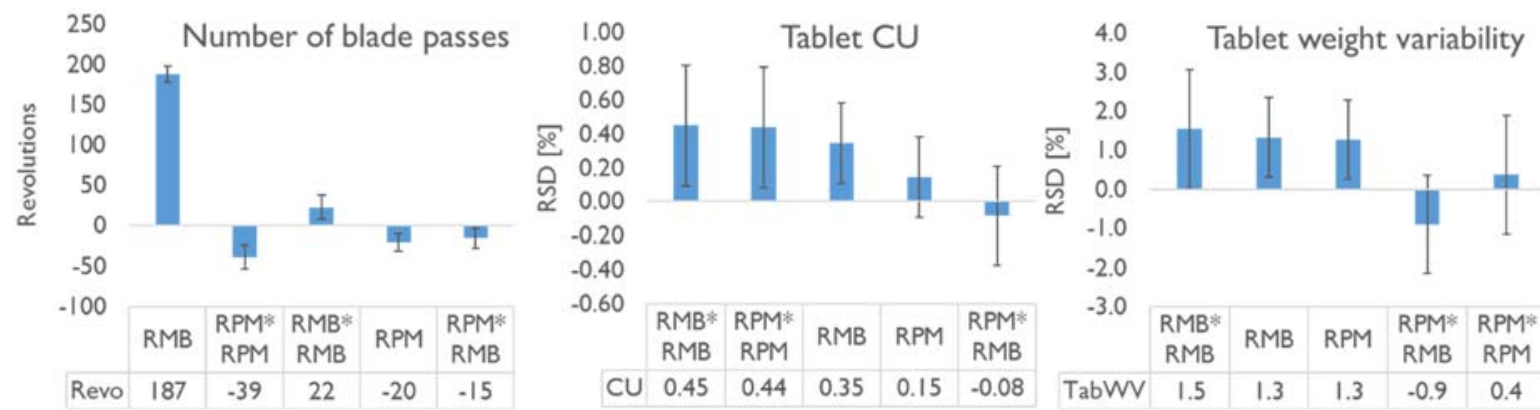

Number of blade passes
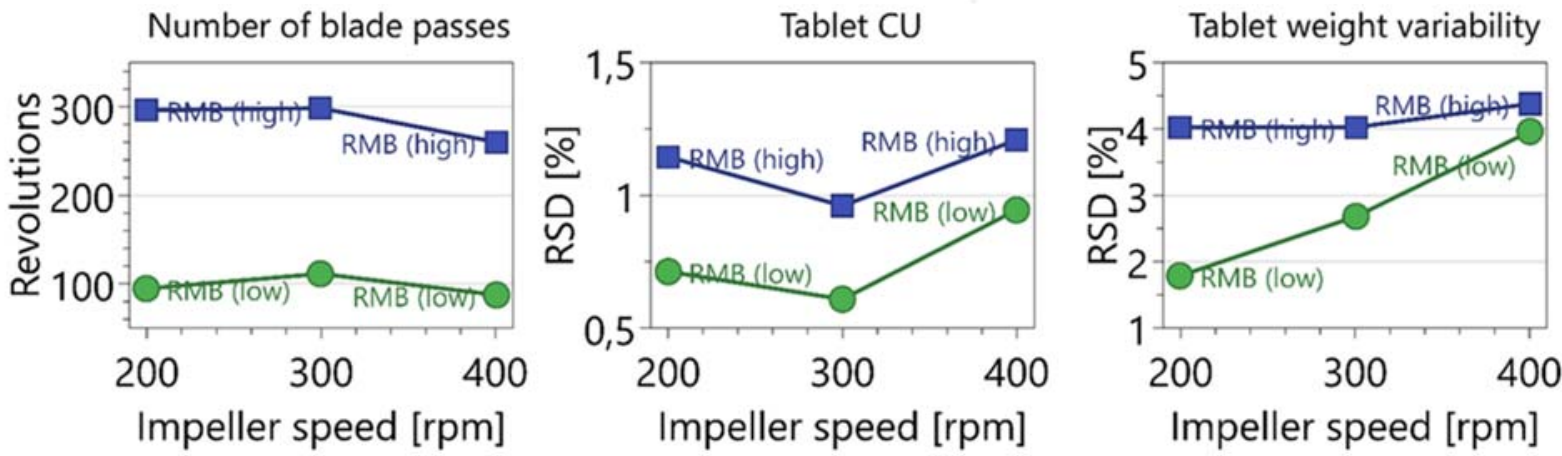

Fig 9: Blending DOE: effect (above) and interaction (below) plot for responses strain (left), tablet CU ( RSD $_{\text {cu }}$, middle) and tablet weight variability ( RSD $_{\text {wv }}$, right). The table presents the size of the effect. 

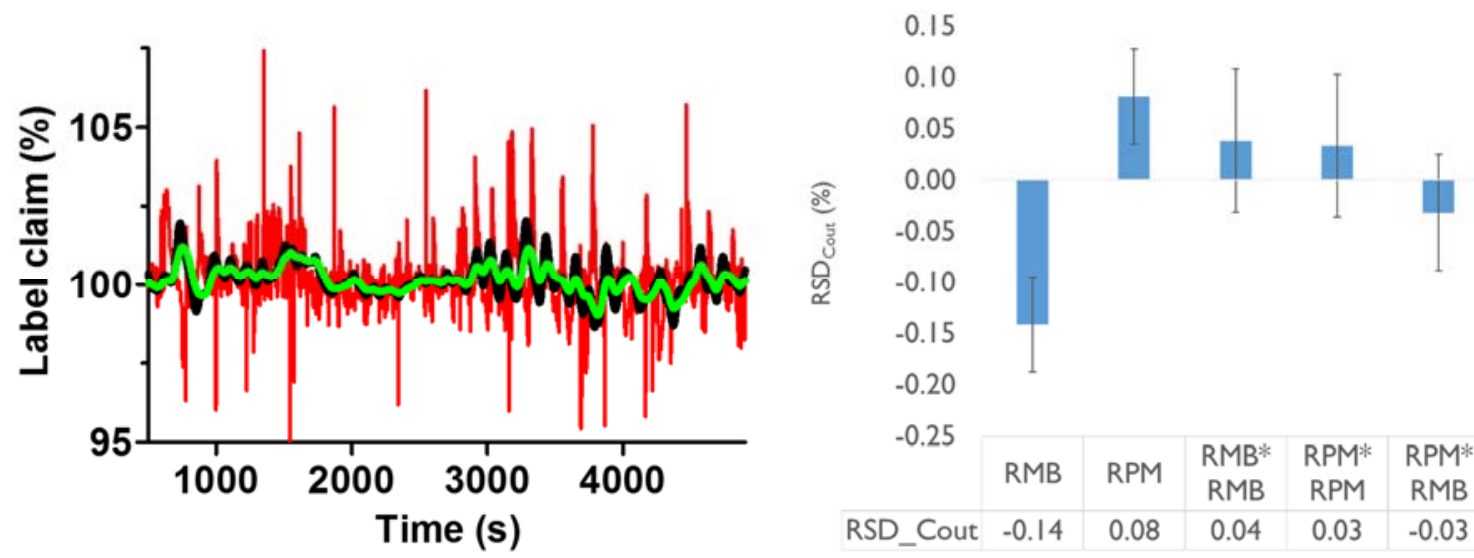

Figure I0: RTD model based macro-mixing evaluation. Left: NAP+SiO2 (\%) label claim as a function of time in feed stream (-) and in blender outlet stream using $8(-)$ and 16 RMB (-) at 400 rpm. Right: Blending DOE: effect size and plot for response NAP+SiO2 (\%) variability in outlet stream (RSD cout). 

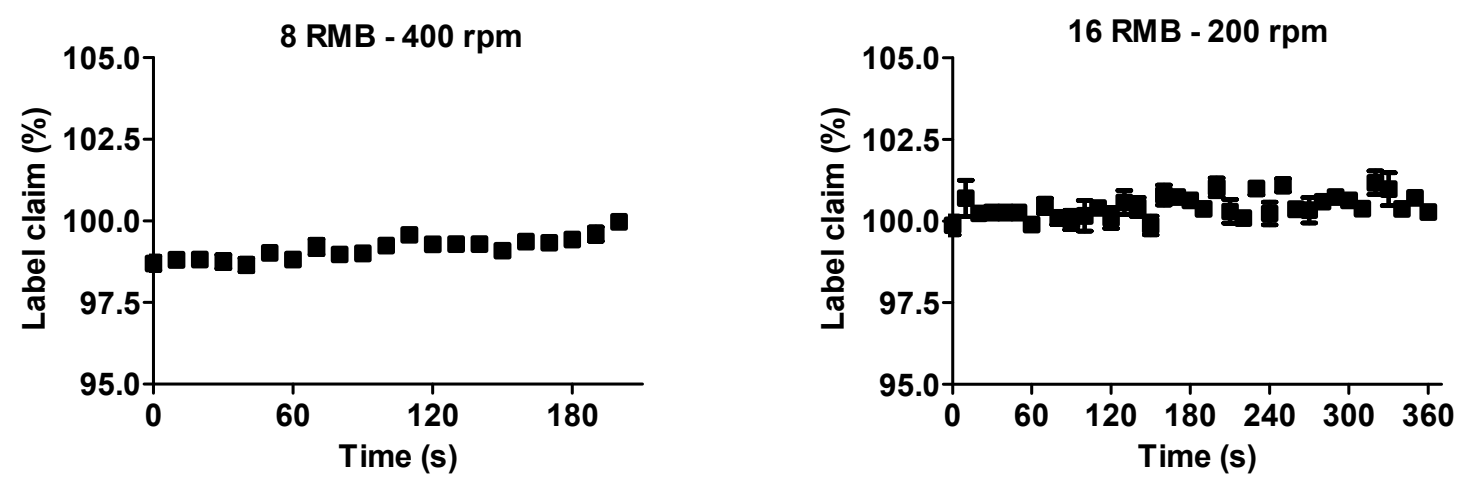

Figure II: Content uniformity analysis as macro-mixing verification. Mean tablet content $(n=10)$ and RSD (error bars) as function of process time. Left and right represent low and high axial mixing condition. 

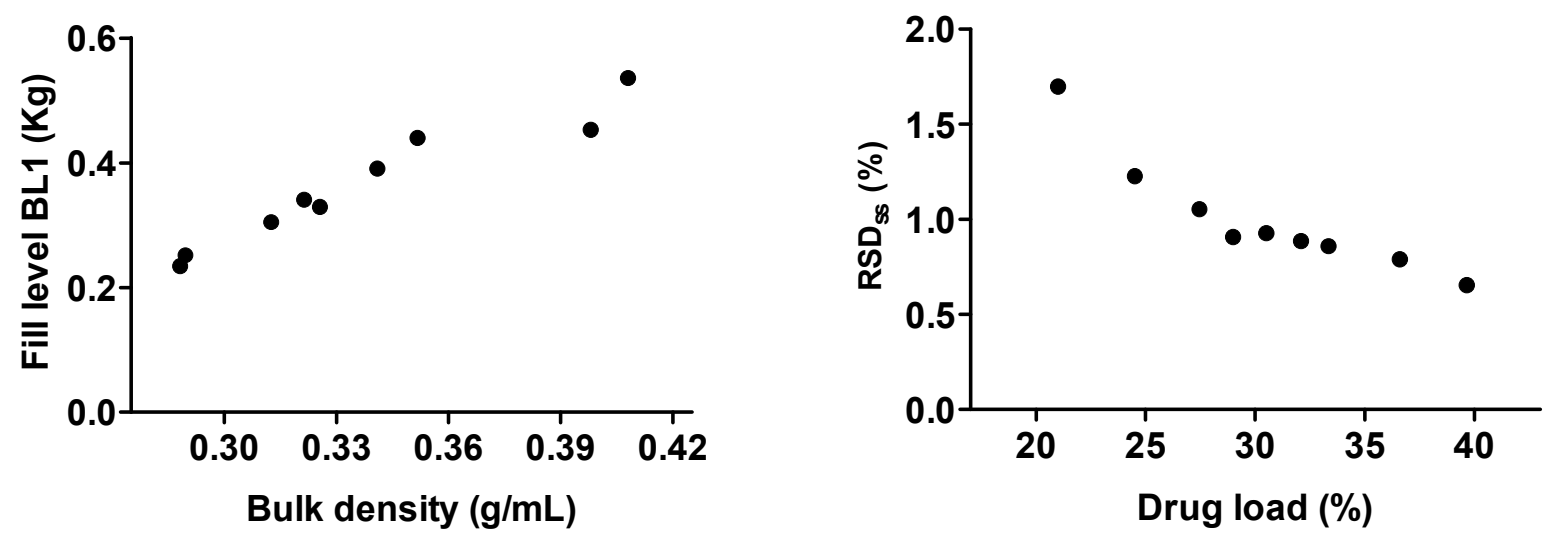

Figure 12: Left: impact of the bulk density of the blend on the steady state fill level in the continuous mixer. Right: steady state blend uniformity determined via NIRs as a function of drug load. 

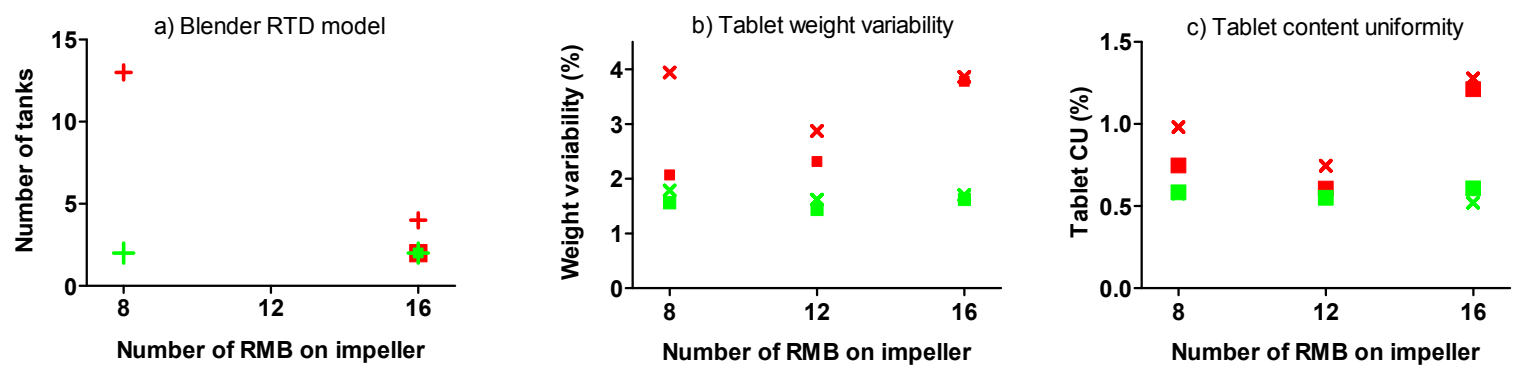

Figure 13: Impact of HPMC grade on process and product responses: a) Number of tanks for optimal model fit of blender RTD, b) tablet weight variability, c) tablet content uniformity. Legend: (x) DC2 400 rpm, (+) DC2 - 300 rpm, ( $)$ DC2 - 200 rpm, (x) CR - 400 rpm, (+) CR - 300 rpm and (घ) CR $-200 \mathrm{rpm}$. 

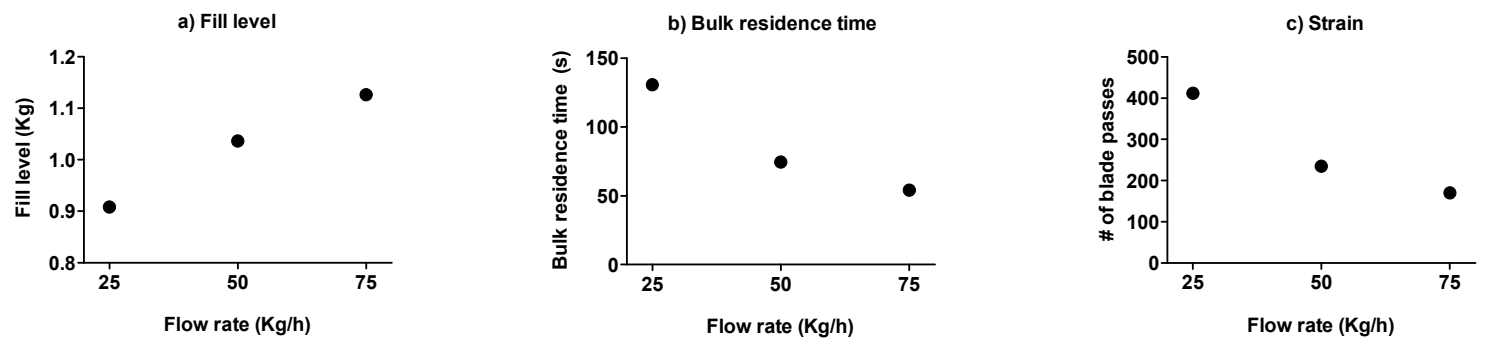

Figure 14: Effect of flow rate on fill level (a), bulk residence time (b) and number of blade passes (c) in blender I $(\bullet)$. 
a) Tabletability

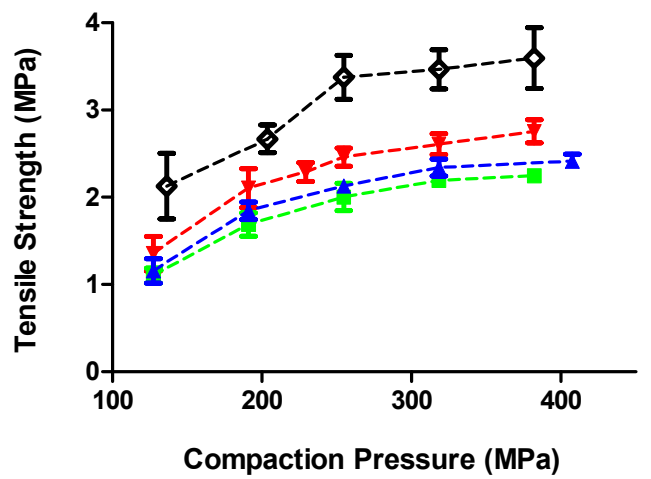

c) Compressibility

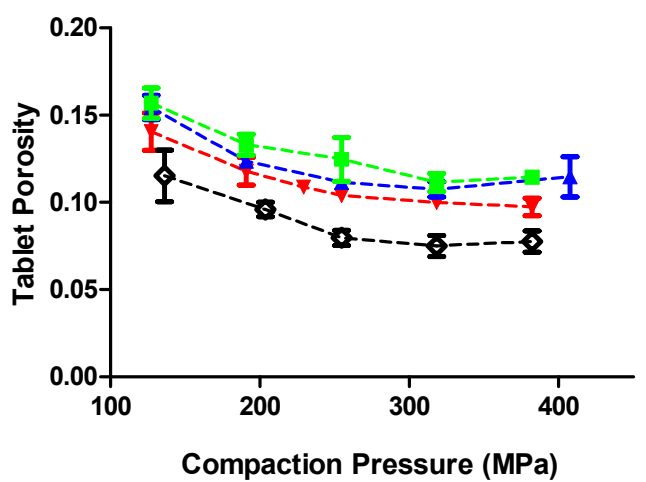

b) Immediate axial recovery (\%)

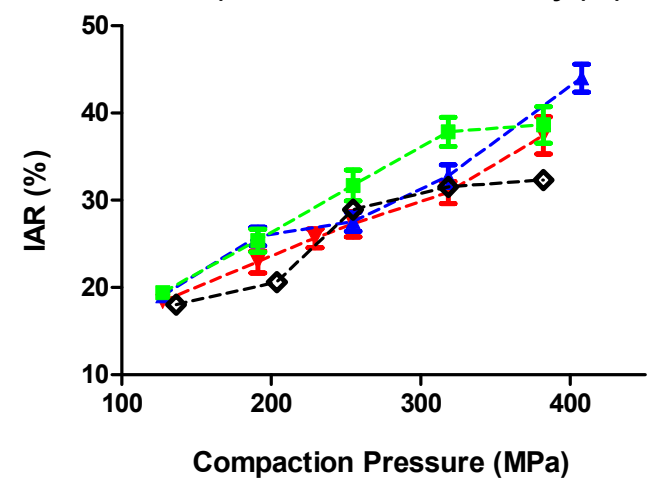

d) Compactibility

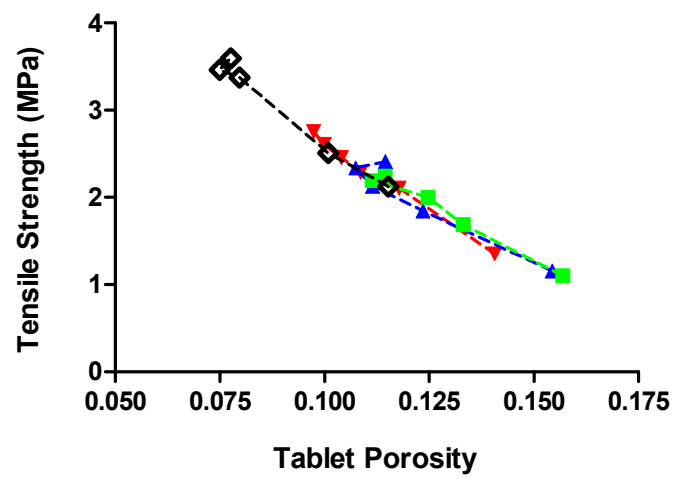

Figure 15: Tabletability (a), immediate axial recovery (b), compressibility (c) and compactibility (d) plot for HPMC DC2 processed at $25(\nabla), 50(\Delta)$ and $75(\square) \mathrm{kg} / \mathrm{h}$ and HPMC CR $(\diamond)$ at $25 \mathrm{~kg} / \mathrm{h}$. Error bars indicate standard deviation $(n=10)$. 
Flow rate $25 \mathrm{Kg} / \mathrm{h}$

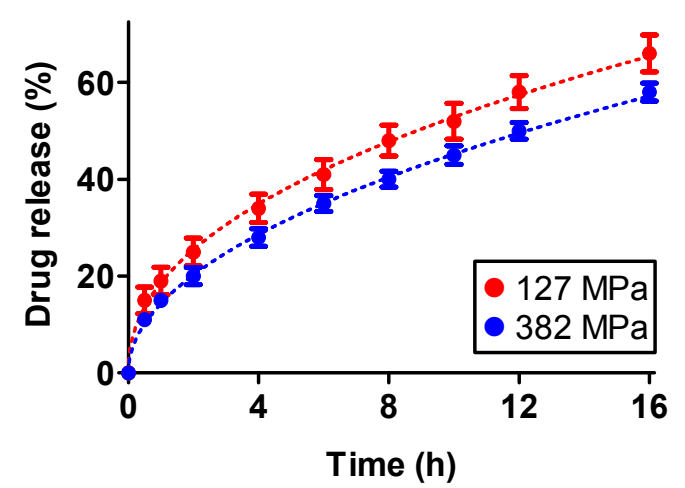

Flow rate $75 \mathrm{Kg} / \mathrm{h}$

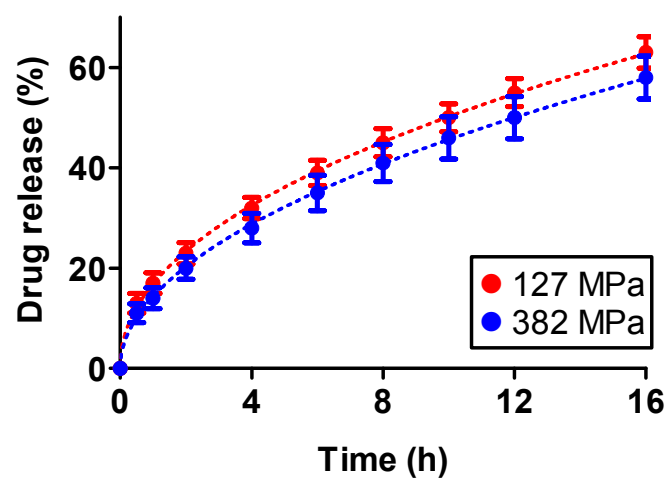

Figure 16: Experimental drug release $(\bullet)$ and model fit (---). Flowrate set at 25 (left) and 75 (right) $\mathrm{kg} / \mathrm{h}$. Color coding according to main compaction pressure. 


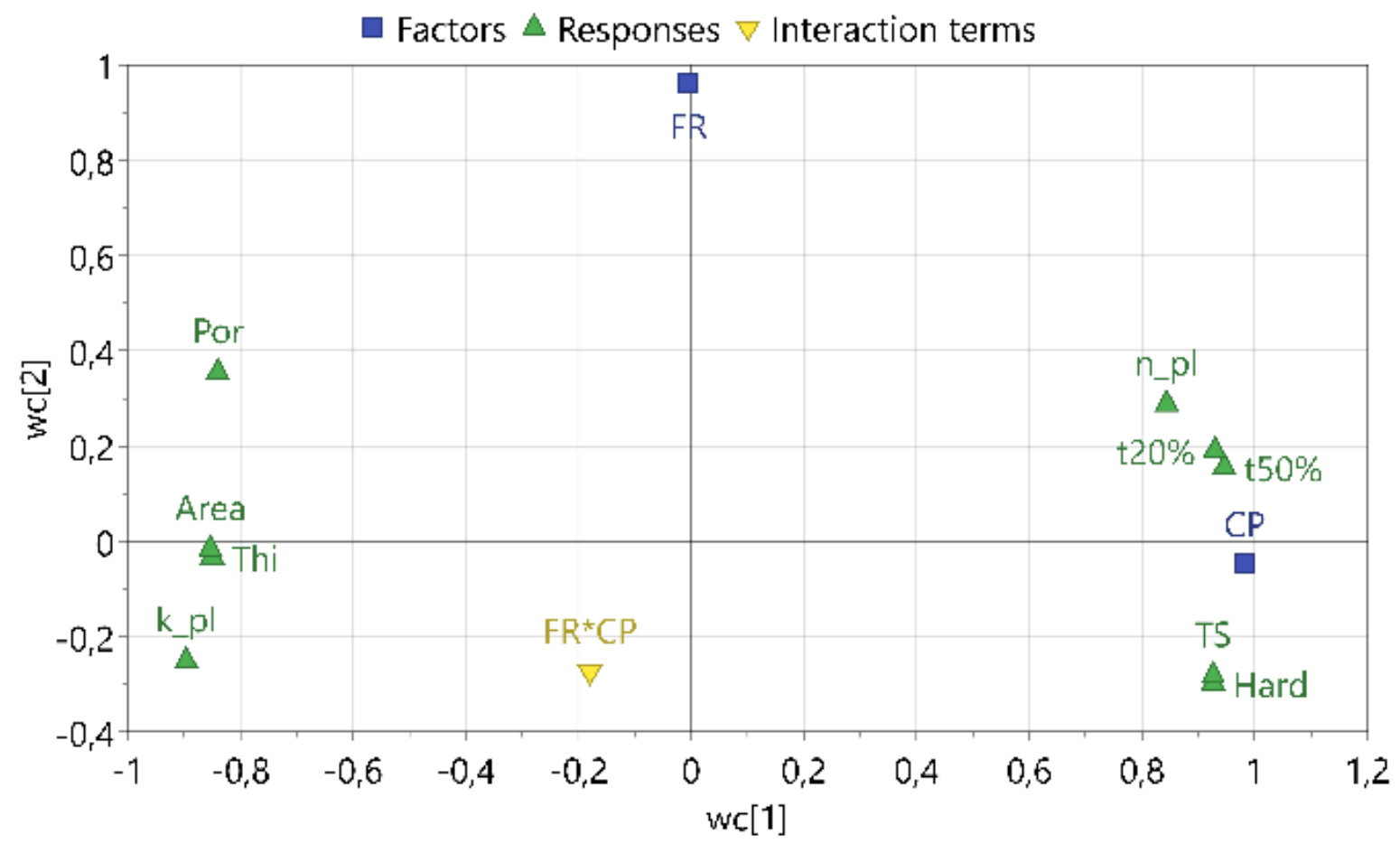

Figure 17: Tablet quality DOE: loading plot of PLS model. Responses and abbreviations ranked according to $\mathrm{R}^{2}$ : tensile strength $(\mathrm{TS})=0.94$, hardness $(\mathrm{Hard})=0.94$, time to release $50 \%$ drug $(\mathrm{t} 50 \%)$ $=0.92$, time to release $20 \%$ drug $(\mathrm{t} 20 \%)=0.90$, kinetic constant power law model $\left(\mathrm{k} \_\mathrm{pl}\right)=0.87$, tablet porosity $($ Por $)=0.83$, release exponent power law model $\left(n \_p l\right)=0.79$, tablet area (Area) $=0.73$, thickness $($ Thi $)=0.72$. The factors compaction pressure and flow rate were abbreviated as CP and FR. 


\begin{tabular}{|c|c|c|c|c|c|}
\hline Material & $\mathbf{f f}_{\mathbf{p}}$ & $\boldsymbol{\rho}_{\text {bulk }}$ & $\mathbf{f f c}$ & $\mathbf{d 5 0}$ & HR \\
\hline Methocel CR & 1.46 & 0.30 & $4.8 \mathrm{I}$ & 82 & $\mathrm{I} .36$ \\
\hline Methocel DC2 & 1.95 & $0.3 \mathrm{I}$ & 6.18 & 102 & $\mathrm{I} .27$ \\
\hline FF316 & $4.8 \mathrm{I}$ & 0.63 & 7.64 & 88 & $\mathrm{I} .13$ \\
\hline NAP & 0.36 & 0.25 & $\mathrm{I} .43$ & 13 & $\mathrm{I} .37$ \\
\hline NAP+SiO2 & 0.57 & 0.25 & 2.28 & 13 & 1.76 \\
\hline MgSt & 0.42 & 0.19 & $2.2 \mathrm{I}$ & 8 & $\mathrm{I} .65$ \\
\hline Starch1500 & 2.35 & 0.62 & $3.8 \mathrm{I}$ & 65 & 1.29 \\
\hline
\end{tabular}

Table I. Key material properties of individual raw materials. 


\begin{tabular}{|c|c|c|c|c|}
\hline Material & $\begin{array}{c}\text { Flow rate } \\
\text { range } \mathbf{( k g / h )}\end{array}$ & $\begin{array}{c}\text { Screw pitch } \\
\mathbf{( m m )}\end{array}$ & $\begin{array}{c}\text { Max feed factor } \\
\text { (g/revolution) }\end{array}$ & $\begin{array}{c}\text { Drive command (\%) at } \\
\text { flow rate ranges }\end{array}$ \\
\hline Methocel CR & $7.5-22.5$ & 20 & 1.36 & $20.0-59.9$ \\
\hline Methocel DC2 & $7.5-22.5$ & 20 & 1.34 & $20.1-60.4$ \\
\hline $\mathrm{FF3I6}$ & $7.25-21.75$ & 20 & 2.12 & $12.3-37.0$ \\
\hline $\mathrm{MgSt}$ & $0.125-0.375$ & 20 & 0.84 & $0.5-1.6$ \\
\hline $\mathrm{MgSt}$ & $0.125-0.375$ & 10 & 0.35 & $1.3-3.9$ \\
\hline $\mathrm{NAP}$ & $7.5-22.5$ & 20 & 0.64 & $42.2-126.5$ \\
\hline NAP+SiO2 & $7.75-22.88$ & 20 & 1.08 & $25.9-76.4$ \\
\hline Starch I500 & $2.5-7.5$ & 20 & 2.98 & $3.0-9.1$ \\
\hline Starch I500 & $2.5-7.5$ & 10 & 1.48 & $6.1-18.3$ \\
\hline
\end{tabular}

Table 2. Overview of flow rate ranges covered in this study and their corresponding drive command estimated using the maximum feed factor. A screw speed of $462 \mathrm{rpm}$ corresponds to $100 \%$ drive command. 


\begin{tabular}{|c|c|c|c|}
\hline Target (\%w/w) & Predicted (\%w/w) & Bias (\%w/w) & RMSEP(\%w/w) \\
\hline 21.00 & 20.84 & 0.16 & 0.40 \\
\hline 24.50 & 24.41 & 0.09 & 0.31 \\
\hline 27.45 & 27.34 & 0.11 & 0.29 \\
\hline 28.98 & 28.79 & 0.19 & 0.33 \\
\hline 30.5 - "Day I" & 30.49 & 0.01 & 0.44 \\
\hline 30.5 - "Day 2" & 30.49 & 0.01 & 0.26 \\
\hline 30.5 - "Day 3" & 30.35 & 0.15 & 0.34 \\
\hline 32.08 & 31.12 & 0.96 & 1.00 \\
\hline 33.35 & 34.37 & -1.02 & 0.86 \\
\hline 36.60 & 37.30 & -0.70 & 0.76 \\
\hline 39.65 & 39.26 & 0.39 & 0.46 \\
\hline
\end{tabular}

Table 3. Verification of in-line NIRs blend uniformity model: NAP target and predicted concentration, bias and RMSEP. 
